\title{
Low temperature growth of carbon nanotubes - A review
}

\author{
Muhammad Ahmad a, S. Ravi P. Silva ${ }^{a, b, *}$ \\ ${ }^{a}$ Advanced Technology Institute, University of Surrey, Guildford, Surrey, GU2 7XH, United Kingdom \\ ${ }^{\mathrm{b}}$ Department of Electrical and Electronic Engineering, University of Surrey, Guildford, Surrey, GU2 7XH, United Kingdom
}

\section{ART I C L E IN F O}

Article history:

Received 16 September 2019

Received in revised form 7 November 2019

Accepted 21 November 2019

Available online $\mathrm{xxx}$

\begin{abstract}
A B S T R A C T
Carbon nanotubes (CNTs) have gained much interest from academia and industry due to their unique properties that include high electrical and thermal conductivity, high mechanical strength, high aspect ratio, high surface area and chemical resistance. Although composite structures containing CNTs are probably the most commercially advanced applications in the market, the area that holds most promise is in electronic applications. Low temperature CVD growth of high quality CNTs can be utilized in many applications particularly next generation IoTs, wearable electronic devices, TSVs, interconnects, and sensors. CNT growth temperature generally reported in literature ranges from 600 to $1000{ }^{\circ} \mathrm{C}$, which is not suitable for temperature sensitive substrates. However, there is ongoing research to achieve CNT growth at low temperatures, with a number reporting the growth below $550{ }^{\circ} \mathrm{C}$. In this review, we examine and discuss various techniques and approaches adopted to achieve growth of carbon nanotubes at low temperatures and its effect on various parameters of CNTs.
\end{abstract}

(C) 2019

\section{Introduction}

Carbon nanotubes can be viewed as rolled up sheets of graphene forming a hollow cylindrical structure, comprising either single shell (SWCNTs) or multi-shells (MWCNTs). In addition of inherited graphene characteristics arising from $\mathrm{sp}^{2}$ bonding, CNTs possess their own unique properties due to their chirality and curvature which dictate their bandgap due to the periodic boundary conditions in the circumferential direction [1]. This becomes the main distinguishing feature of CNTs that, contrary to graphene, they can be either metallic or semiconducting depending on their chirality [2]. This opens up a wider application scope of CNTs, especially in electronics where CNTs can both be used as active semiconductor and as interconnects for charge transport, since semiconducting CNT based field-effect transistors have already been demonstrated and metallic CNTs have potential to be used as interconnects [3]. The conduction in defect-free CNTs is ballistic with high current carrying capacity $(\sim 3$ orders of magnitude higher than $\mathrm{Cu}$ ) [4]. CNTs are high aspect ratio nanostructures with their length ranging from sub-micrometer to centimeters and their diameter from 1 to $30 \mathrm{~nm}[1,5]$. Thermal conductivity of CNTs has been reported as high as $3500 \mathrm{Wm}^{-1} \mathrm{~K}^{-1}$ and a tensile strength of $100 \mathrm{GPa}$ $[6,7]$. Such excellent and unique properties of CNTs have attracted applications in many areas such as electronics [8], interconnects [8], flexible plastic electronics [8,9], sensors [9], conductive ink for ink-

\footnotetext{
* Corresponding author. Advanced Technology Institute, University of Surrey, Guildford, Surrey, GU2 7XH, United Kingdom.

E-mail address: s.silva@surrey.ac.uk (S.RaviP. Silva)
}

jet printing [9], transparent electrodes [10], electromagnetic shielding [8], aeronautics and astronautics [11], microwave absorption [12], battery electrodes and supercapacitors $[8,10]$, Pt catalyst support for methanol fuel cells [13], composite materials [8], paints and coatings [8], wearables and IoTs $[14,15]$. CNT based flexible wearable strain sensors to detect human motion has been demonstrated (Fig. 1a, b) [16].

Growth of defect-free long CNTs can be utilized to make high conductivity light weight and strong cables for electrical power transmission, and to turn the dream of space-elevator into reality (Fig. 1c) [23]. CNT yarns $[17,24]$ have great potential in realizing smart fabric $[25,26]$, artificial muscles [27] and electrochemically harvesting electrical energy (Fig. 1d, e) [18]. CNTs are also paving their way in the field of flexible printed electronics and sensors (Fig. 1f) [19,28]. CNTs are being utilized to fabricate nano-scale devices for progressive technology such as atomic scale mass sensors (Fig. 1g) [20]. Vantablack (Fig. $1 \mathrm{~h}$ ), a super-black CNT coating that holds the world record as the darkest man-made substance has found its widespread applications such as stray light suppression, aesthetic applications, sensors, telescope, spectroscopy, camera lenses etc. $[21,29]$. CNT based composite materials are being commercialized for bicycle frames (Fig. 1i), paints and electrostatic discharge shielding [8].

There are several articles comprising a thorough review of CNT growth and their applications [8,30-33], however relatively fewer give a detailed account on the low temperature $\left(0-500{ }^{\circ} \mathrm{C}\right)$ growth of carbon nanotubes [34-37]. In this paper, at first we present a brief overview of CNT growth techniques with CVD method as our center of attention and then a detailed review of various CVD methods adopted for the growth of CNTs at low temperatures. 

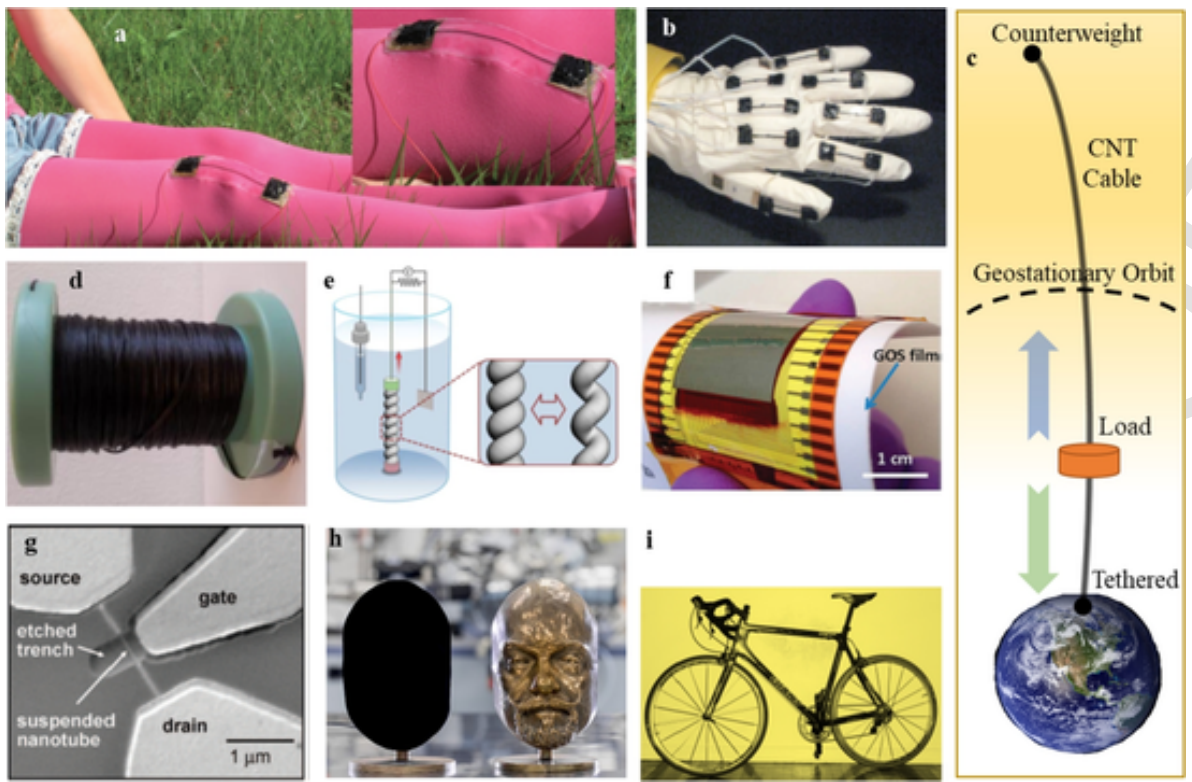

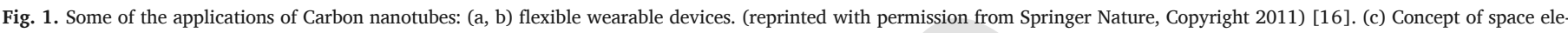

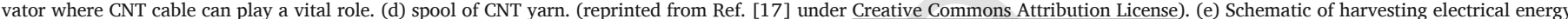

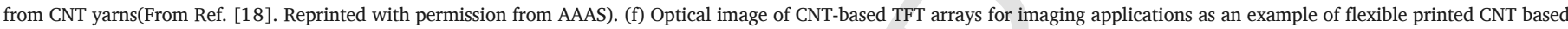

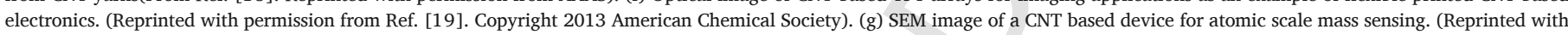

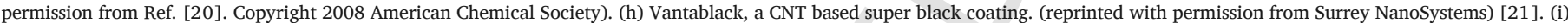
CNTs are used to make bicycle frames [22].

\section{Growth of CNTs}

Since their formal discovery in 1991, outstanding progress has been seen in the development of CNT growth processes. There are mainly three CNT production methods: (i) Arc discharge, (ii) Laser ablation and (iii) Chemical vapor deposition (CVD). Schematics of these methods are shown in Fig. 2. In the arc discharge and laser ablation methods, high temperatures $\left(3000-4000{ }^{\circ} \mathrm{C}\right.$ ) are used to evaporate a solid carbon source which results in the synthesis of CNTs upon condensation, whereas CVD involves pyrolysis of a carbon source on catalyst nanoparticles in the temperature range of $600-1100{ }^{\circ} \mathrm{C}$ [30,38-42]. In the arc discharge method (Fig. 2a), two carbon rods (electrodes) are placed end to end with a small gap between them in a low-pressure inert gas environment. Upon passing a DC current (50-100 A) between the electrodes, high speed electrons emitted from cathode hit the anode which evaporate it by increasing its temperature. A part of the evaporated carbon is converted to CNTs upon condensation on the cathode. In the laser ablation method (Fig. 2b), a laser beam is focused on a solid carbon target doped with a metal catalyst to evaporate it in a buffer gas (Ar) environment. Upon condensation, the catalyst particles are attached to the carbon atoms to facilitate the synthesis of CNTs.

CVD growth (Fig. 2c) strategies involve the CNT growth on nanoparticles of a metal catalyst such as $\mathrm{Fe}, \mathrm{Ni}, \mathrm{Co}$, at temperatures $600-1100{ }^{\circ} \mathrm{C}$ in a hydrocarbon gas environment [30]. Catalyst heat-treatment in a reducing gas environment (e.g. $\mathrm{H}_{2}, \mathrm{NH}_{3}$.) is generally required for the formation of active nanoparticles. After the heat-treatment, a carbonaceous gas is introduced in the reaction chamber for the growth of CNTs. An oxide support layer such as $\mathrm{SiO} 2, \mathrm{Al} 2 \mathrm{O} 3$ is often employed under the catalyst; CNT growth on conductive support layers is relatively challenging. CVD is a preferred growth method for being able to produce CNTs at relatively low temperatures with greater control over growth parameters and for its ability to grow CNTs on predefined areas on a substrate. CNT growth at lower temperatures $\left(25-500{ }^{\circ} \mathrm{C}\right)$ is required for many potential applications such as flexible electronic devices, sensors, integrated circuit interconnects and a

Arc Discharge Method

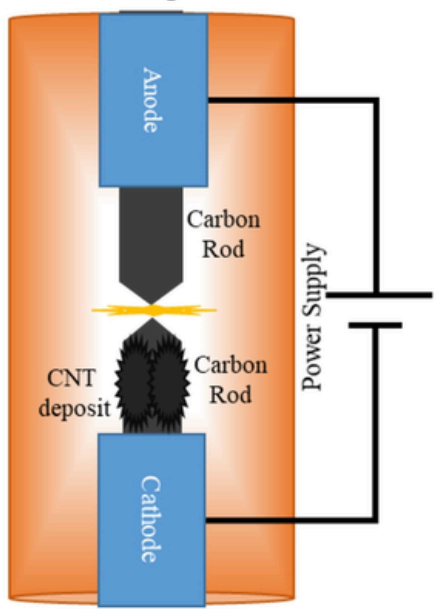

c

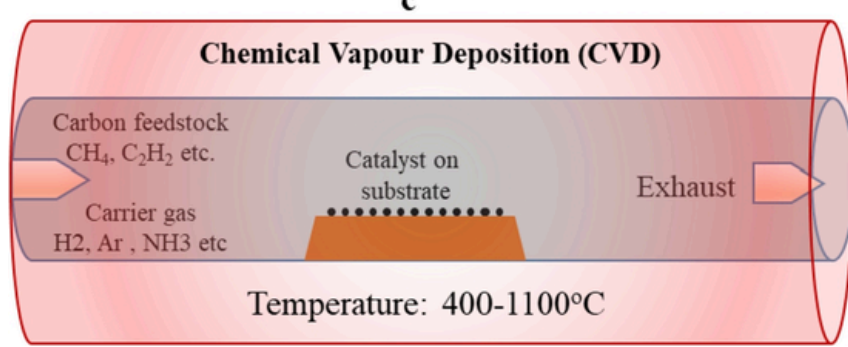

Fig. 2. Schematic of CVD setup where a carbonaceous gas mixed with carrier gases are introduced at high temperature $\left(600-1100^{\circ} \mathrm{C}\right)$ in the furnace and growth of CNTs occurs on catalyst nanoparticles. (A colour version of this figure can be viewed online.)

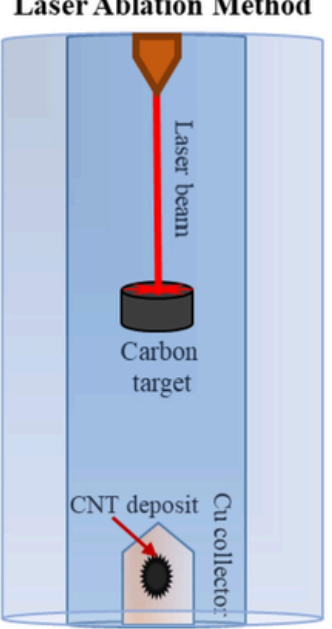

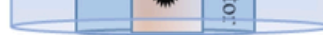


through $\mathrm{Si}$ vias. A timeline displaying some of the milestones achieved in the growth history of CNTs is shown in Fig. 3.

\section{CVD growth of CNTs}

CVD is an established technique in the semiconductor industry to produce high quality thin films of different materials such as silicon, tungsten, carbides, oxides and nitrides. After the formal discovery of CNTs in 1991 by arc discharge method [43], CVD method was readily adopted for the growth of CNTs [45] and developed throughout the years by utilizing its different forms such as thermal CVD (TCVD), plasma enhanced CVD (PECVD), photothermal CVD (PTCVD) [57-61], aerogel-supported CVD [62], aerosol-assisted (AA)CVD [63-65], laser assisted CVD [66], alcohol catalytic CVD [67] and remote plasma CVD [58]. TCVD and PECVD are the most commonly used techniques for CNT growth $[33,45,68]$. For CVD growth of CNTs, a metal catalyst such as $\mathrm{Fe}, \mathrm{Ni}$, is used and a carbonaceous substance is introduced to the reaction chamber for the growth of CNTs. The metal catalyst can either be deposited on a substrate (supported catalyst) or introduced directly in the reaction chamber in vapor form (floating catalyst) [69-71]. The carbon feedstock and metal catalyst can either be introduced simultaneously in the reaction chamber, e.g. in AACVD and floating catalyst method or in two steps where the catalyst supported on a substrate is placed first. The floating catalyst method and AACVD offers an advantage of continuous CNT production, as both the carbon source (e.g. xylene, toluene, $\mathrm{CH}_{4}$ ) and the catalyst (e.g. ferrocene) can be supplied continuously in the reaction chamber, whereas the supported catalyst method offers greater control over CNT parameters and growth sites, as the catalyst can be deposited on the pre-defined locations on a substrate. In the supported catalyst method, a thin film of a metal catalyst is deposited on a suitable substrate followed by the catalyst pre-treatment or reduction in the CVD reaction chamber to turn the thin catalyst film into active nanoparticles by thermal annealing, chemical etching, and/or plasma treatment. The temperature required for the CVD growth of CNTs usually ranges from 600 to $1100{ }^{\circ} \mathrm{C}$ [72-75]. The choice of carbon source, carrier gas, flow rate, chamber pressure, temperature, substrate material, catalyst material and its thickness, size and distribution of the catalyst nanoparticles, catalyst support material and temperature are some of the key parameters that affect growth rate, height, quality, density, diameter, number of walls and conductivity type (metallic or semiconducting) of carbon nanotubes [76-79].

A generally accepted CNT growth mechanism is illustrated in Fig. 4. Under high temperature conditions decomposition of a

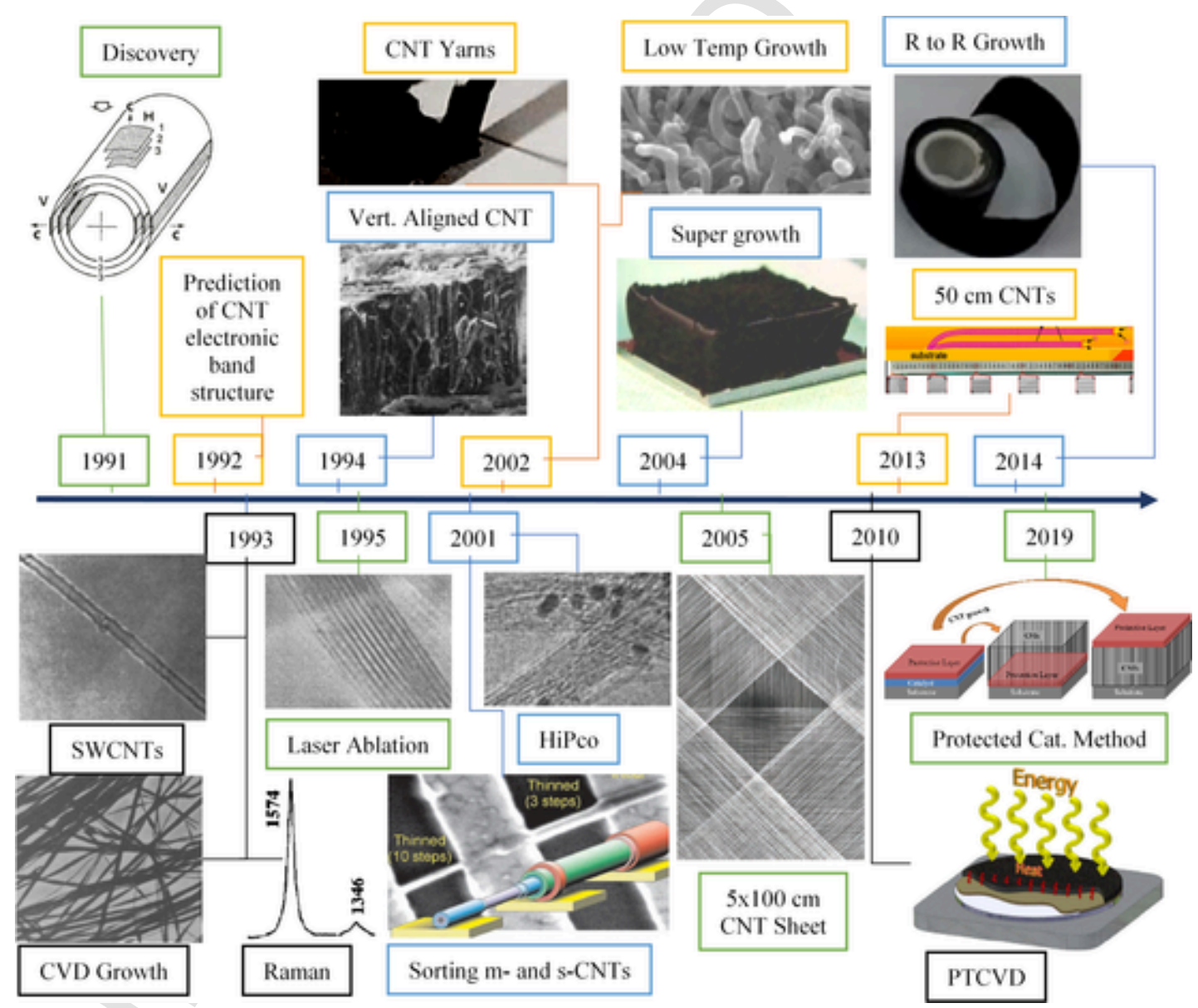

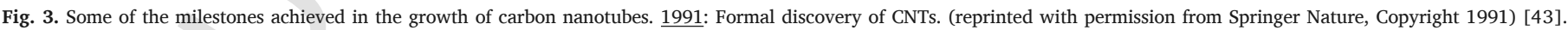

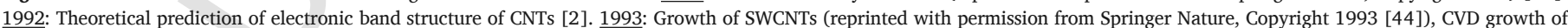

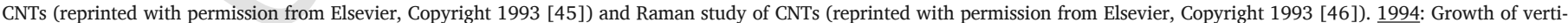

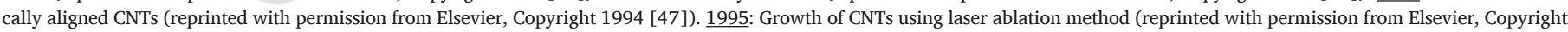

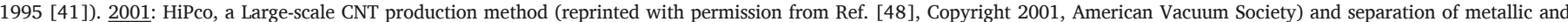

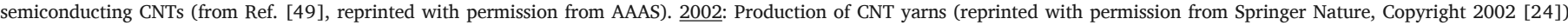

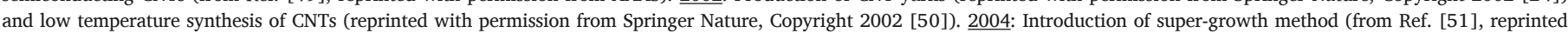

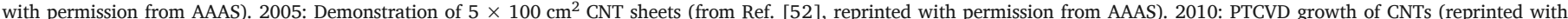

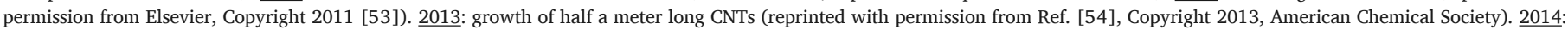

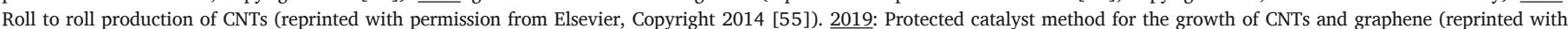
permission from Elsevier, Copyright 2019 [56]). (A colour version of this figure can be viewed online.) 

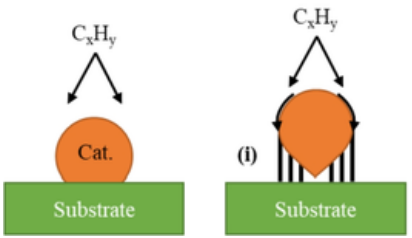

(ii)
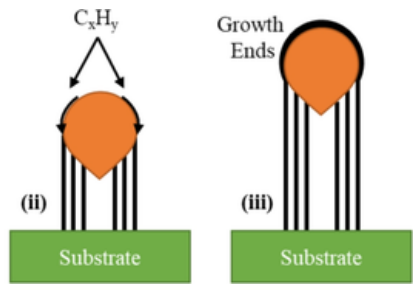

Fig. 4. Schematic of the growth mechanism of CNTs: (i) Decomposition of carbon feedstock, diffusion and graphitization. (ii) CNT growth (iii) Growth Ends [33].

hydrocarbons gas on the surface of catalyst nanoparticles occurs to form metastable $\mathrm{C}_{2}$ molecules which diffuse down and precipitate at the other side of the nanoparticles for the growth of carbon nanotubes $[33,42,50,68,80,81]$. If the catalyst particles are not well adhered to the substrate, they are lifted up with the growth of nanotubes which is called "tip growth" mechanism. On the other hand if the particles remain attached to the substrate then it is known as a "base growth" or "root growth" mechanism [33].

All physical forms of carbon sources, that is, gas, liquid and solid, have been utilized for the growth of carbon nanotubes [30]. Carbonaceous gases can be introduced directly in the reaction chamber [76], whereas, liquids are thermally evaporated before their admittance in the chamber $[45,82,83]$. Volatile solids like camphor, naphthalene and ferrocene directly turn to gas and have been used for CNT growth $[84,85]$. The commonly used carbon sources are $\mathrm{C}_{2} \mathrm{H}_{2}, \mathrm{CH}_{4}, \mathrm{CO}, \mathrm{C}_{2} \mathrm{H}_{4}$, benzene, camphor and ethanol [33]. Over the years, remarkable progress has been made in the development of high yield scale-able CNT growth methods with better controls (Fig. 3). In the 'super growth' method, growth rates higher than $200 \mu \mathrm{m} / \mathrm{min}$ have been achieved [51,86]. CNTs with lengths up to half a meter reported [5,54]. Several CVD growth processes has been scaled up for the commercial production of CNTs with a production capacity as high as $16 \mathrm{~kg} / \mathrm{h}$ [33]. Synthesis of MWCNTs as well as SWCNTs have been achieved using CVD techniques [60,87-90]. Roll-to-roll production of MWCNTs on aluminum foil has been demonstrated using a ferrocene-xylene liquid injection floating catalyst technique $[55,63]$.

The most commonly used catalyst materials for CNT growth are $\mathrm{Fe}$, $\mathrm{Ni}$ and $\mathrm{Co}[33,42]$. However, other materials such as $\mathrm{Cu}, \mathrm{Ag}, \mathrm{Au}, \mathrm{Pt}$ and Pd have also been used for this purpose [91]. The catalytic ability of these materials is believed to depend on diffusion and solubility of carbon within the catalyst. Also, catalyst nanoparticles are supposed to offer strong adhesion to the carbon atoms of growing CNTs which results in the formation of high curvature tubular structure of CNTs and that is why CNT diameter is generally found equal to the diameter of catalyst nanoparticles [33]. A thin film of usually $0.5-10 \mathrm{~nm}$ of catalyst is deposited either by physical vapor deposition (PVD) techniques such as evaporation, sputtering or by solution based methods. PVD is relatively more common method which involves vaporization of catalyst material through thermal or electrical energy under low pressure and subsequent deposition on a substrate. Solution based techniques involve direct coating of catalyst using one of various techniques such as spin coating, spray coating, dip coating and drop casting. Catalyst pretreatment is generally performed for $10-60 \mathrm{~min}$ at $550-900{ }^{\circ} \mathrm{C}$ for the formation of active nanoparticles, prior to the growth of CNTs [76,92-94]. The size and the geometry of the nanoparticles depend mainly on the annealing temperature, duration [95], environment [96] and the catalyst film thickness [76]. The other important parameter is the reduction (de-oxidation) of the catalyst particles which is accomplished by annealing the catalyst in a reducing gas environments, such as $\mathrm{H}_{2}$ and $\mathrm{NH}_{3}[76,96]$.

Common substrates for CNT growth in CVD include $\mathrm{Si}, \mathrm{Al}_{2} \mathrm{O}_{3}$, quartz, silicon carbide and zeolite [33,42]. A suitable substrate is one that controls the agglomeration of catalyst particles, inhibits catalyst diffusion, prevents alloying and withstands high growth temperatures. Alumina is a good substrate for CNT growth because of its ability to facilitate uniform dispersion of catalyst nanoparticles without degrading the catalytic activity [97]. Si is the most commonly used substrate, however diffusion of the catalyst and formation of metal (catalyst) silicides and silicates at high temperatures hinders the growth if not stopped. To overcome this issue, a buffer layer such as $\mathrm{SiO}_{2}$ is used between the $\mathrm{Si}$ and the catalyst $[42,98]$. Growth of CNTs on metallic substrate layers is relatively challenging and less common $[60,79,99]$. Commonly used metallic layers for the growth of carbon nanotubes are $\mathrm{Cu} / \mathrm{TaN} / \mathrm{TiN}$ [100], $\mathrm{Cu} / \mathrm{Ta}$ [101], CuAl alloy [102], TiN [103] and $\mathrm{Cr}$ (or Ta) [104].

CNTs produced by arc-discharge and laser ablation methods generally show higher crystalline quality as compared with CVD grown CNTs. However, CVD is a versatile and economical technique which can be scaled up easily because of its high yield and low-cost production capabilities. A unique capability of CVD method is that both vertical and horizontally aligned CNTs at predefined substrate locations can be grown (Fig. 5), which allows their direct integration in various applications, for example, interconnects, micro-electrode arrays and optical devices $[37,79,91,102,105-111]$. Selective growth of metallic (m-SWCNTs) or semiconducting (s-SWCNTs) CNTs with controlled diameter, walls, chirality, alignment and density is still challenging. A convenient method for detailed and efficient CNT characterization is as yet unavailable. At present, CNTs are mainly characterized by resonant Raman spectroscopy, SEM, STM and TEM. Raman spectroscopy is a powerful technique which gives structural information of CNTs such as diameter, chirality, structure (MWCNT or SWCNT), defects and structural quality. However, it is limited by the resonance window, environmental effects and inability to provide information of individual CNTs in a bundle. SEM is mainly used to observe length of CNTs, orientation and to estimate their density but it is unable to give accurate information about the diameter, walls, chirality and structural quality. STM allows to determine diameter and chirality of individual tubes whereas TEM is used to find number of walls, diameter and structural quality of CNTs but both of these tools are inefficient because of their operating conditions and sample preparation requirements $[56,112]$.
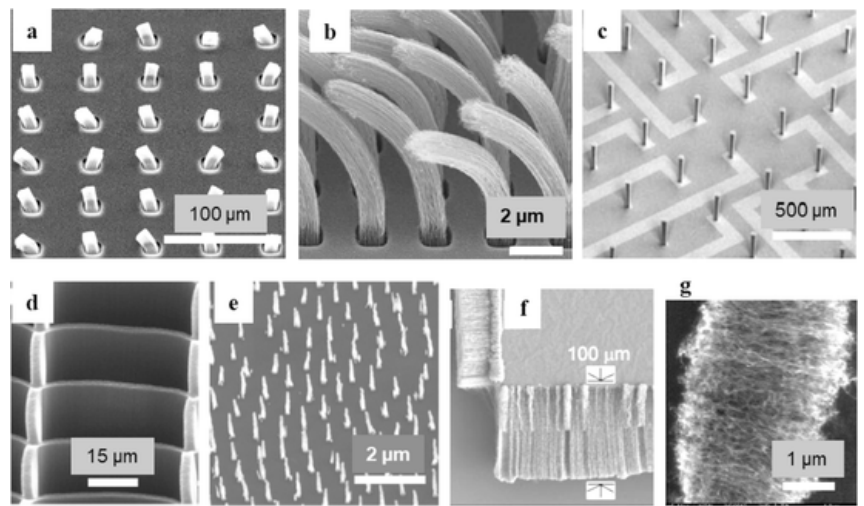

Fig. 5. SEM images showing aligned growth of CNTs. (a) Vertically aligned CNTs (VCNT) grown by us. (b) VCNTs grown by Dijon et al., for interconnect via application (reproduced with permission from Ref. [102], Copyright 2010, Elsevier Masson SAS. All rights reserved). (c) VCNT based micro-electrode arrays (reprinted with permission from Ref [109]. Copyright (2018) American Chemical Society). (d) VCNT structure grown directly on glass for optical collimation (reprinted from Ref. [111] under Creative Commons Attribution License). (e) Circular arrays of VCNTs to display spatially continuous diffraction patterns in the far field (reprinted from Ref. [108], with the permission of AIP Publishing). (f) Directional control over the growth of CNTs demonstrated by Cao et al. (reprinted with permission from Ref. [107], (C) 2003 WILEY-VCH Verlag GmbH \& Co. KGaA, Wein heim). (g) Growth of horizontally aligned CNTs by us. (A colour version of this figure can be viewed online.) 


\section{Low temperature growth of CNTs}

Low temperature growth of CNTs without compromising their properties has proven to be challenging thus far. Many properties of CNTs such as quality, growth rate, chirality, diameter and length are directly affected by the growth temperature [30]. Referring back to the CNT growth mechanism depicted in Fig. 4, three distinctive stages can be identified namely decomposition of carbon feedstock on the surface of catalyst particles, diffusion of carbon radicals and incorporation of carbon atoms in the growing structure of CNTs. Although all these stages are temperature dependent, the decomposition of carbon feedstock on the catalyst particle is commonly considered as the rate limiting step $[113,114]$. The decomposition depends on the type of chemical reaction of a carbon feedstock, and on the type and size of the catalyst nanoparticles. In other words, key to achieve low temperature growth of CNTs is to have carbon feedstock decomposed on correctly sized catalyst particles formed at lower temperatures. Thus, low temperature growth of CNTs reported in the literature is mainly based on achieving the decomposition at low temperature by selecting suitable reaction species, a suitable method of energy delivery and a suitable catalyst system. Generally, the low temperature growth of CNTs is achieved either by using a carbon feedstock with exothermal decomposition such as $\mathrm{C}_{2} \mathrm{H}_{4}, \mathrm{C}_{2} \mathrm{H}_{2}$, etc., or by plasma assisted decomposition or by engineering design of the growth kit such as multi temperature zone CVD system and PTCVD system. PECVD is a widely researched method which was originally introduced in the semiconductor industry because of its advantage of allowing deposition at low temperatures (room temperature to $300{ }^{\circ} \mathrm{C}$ ). In PECVD, a glow discharge is produced to dissociate precursor gases by applying high voltages across the two electrodes. Despite its ability to dissociate the precursor gases, CNT growth remains challenging below $550{ }^{\circ} \mathrm{C}$ [115-117]. We utilize PTCVD to grow vertically aligned high quality CNTs at low substrate temperatures on a range of substrate materials.

\subsection{CNT growth using thermal CVD}

TCVD based low temperature CNT growth is generally achieved by selecting reaction species which require low decomposition temperature, a suitable catalyst system or a multi-temperature-zone CVD system. Halonen et al. studied low temperature TCVD based CNT synthesis using various carbon feedstocks which include cyclopentene oxide, tetrahydrofuran, methanol, xylene and acetylene [118]. They also performed catalytic activity study of $\mathrm{Fe}$, Co, $\mathrm{Ni}$ as well as their bi- and tri-layer combinations. Monometallic catalysts of $\mathrm{Co}$ and Fe nanoparticles of size $25-28 \mathrm{~nm}$ dispersed in Xylene were drop casted on $\mathrm{Si} / \mathrm{SiO}_{2}$ substrates. The bi- and tri-metallic catalysts were prepared by wet-impregnation and subsequent thermal decomposition of their salts. The growth of CNTs at $400{ }^{\circ} \mathrm{C}$ occurred only when bi-metallic Co-Fe or tri-metallic $\mathrm{Ni}-\mathrm{Co}-\mathrm{Fe}$ catalyst deposited on alumina, and methanol or acetylene as carbon precursors were used. For single layered catalysts, only Co resulted in the growth of CNTs at $470{ }^{\circ} \mathrm{C}$ when cyclopentene oxide was used as carbon feedstock. The produced CNTs were very short $(<1 \mu \mathrm{m})$, tangled and contain high structural defects as determined by Raman spectroscopy, SEM and TEM analysis (Fig. 6a-c). The activation of low temperature growth of CNTs only for certain carbon precursors are associated with their relatively low bond energies, e.g. the low energy C-O bond $(280 \mathrm{~kJ} / \mathrm{mol})$ in cyclopentene oxide is easier to crack as compared with that of $\mathrm{C}-\mathrm{OH}(385 \mathrm{~kJ} / \mathrm{mol})$ of methanol. Various properties of catalyst materials such as size of catalyst nanoparticles, carbon solubility and diffusion rate affect the growth of CNTs. Although not well understood, the role of bi-metallic and tri-metallic catalyst layers on $\mathrm{Al}_{2} \mathrm{O}_{3}$ is thought to facilitate dehydration of methanol which allows decomposition at lower temperatures. Also, the week $\pi$ bonds in acetylene is considered to be responsible to allow growth at lower temperatures [118].

Cartwright et al. reported CNT growth on tetrahedral-amorphous carbon (ta-C) below $500{ }^{\circ} \mathrm{C}$ by using $\mathrm{Fe}-\mathrm{Cu}$ catalyst system and $\mathrm{C}_{2} \mathrm{H}_{2}$ as carbon feedstock [119]. Upon thermal treatment, $\mathrm{Cu}$ forms an alloy with $\mathrm{Fe}$ which enhances the nucleation of carbon atoms and prevent carbon diffusion into the substrate (ta-C). On $\mathrm{Si} / \mathrm{SiO}_{2}$, they
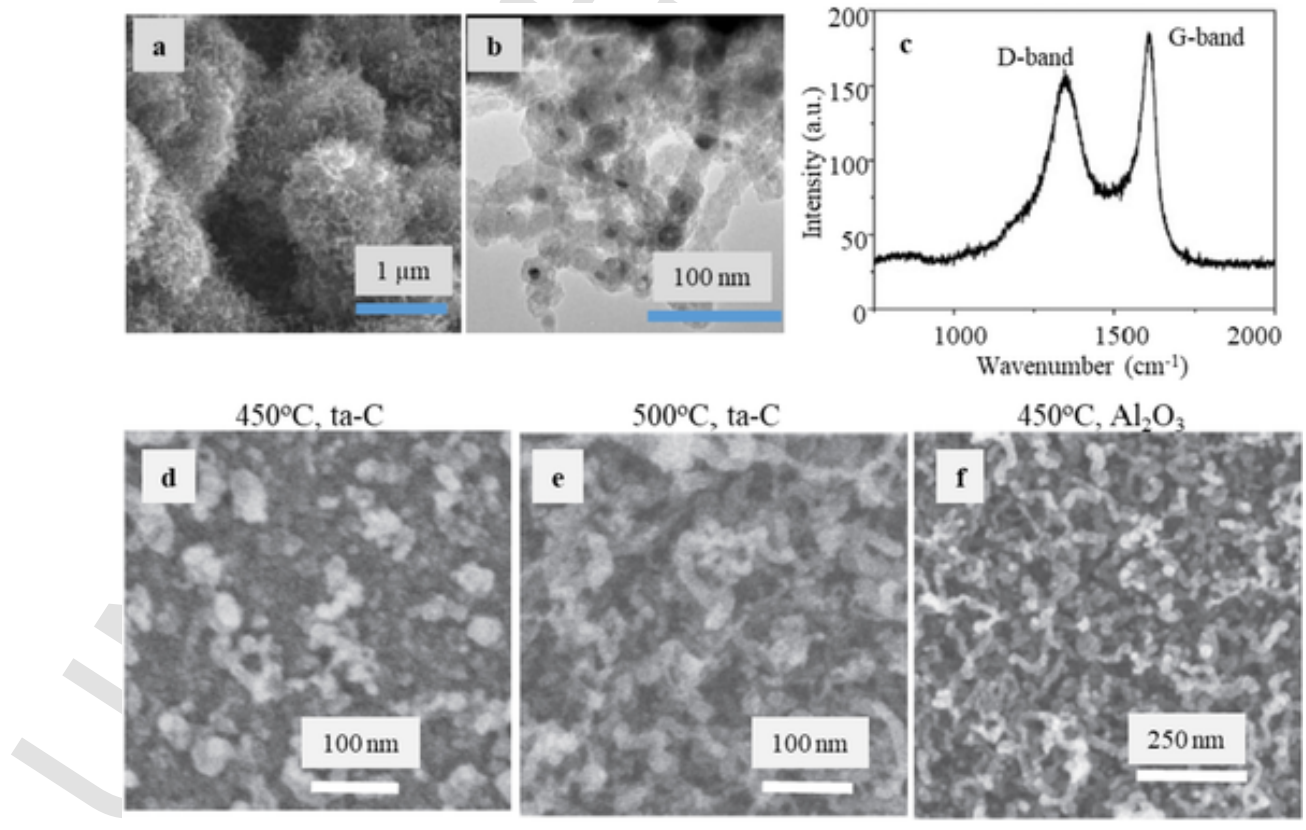

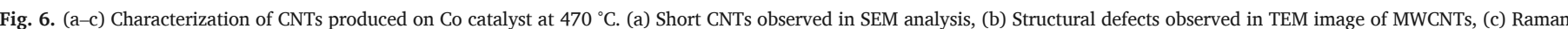

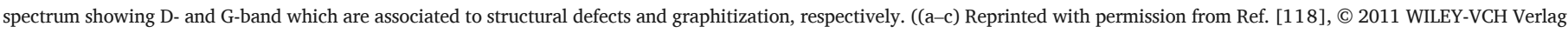

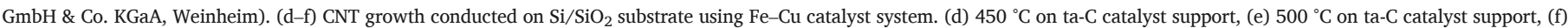
$450{ }^{\circ} \mathrm{C}$ on $\mathrm{Al}_{2} \mathrm{O}_{3}$ catalyst support. ((d-f) Reprinted from Ref. [119], with permission from Elsevier, copyright 2015). (A colour version of this figure can be viewed online.) 
deposited $100 \mathrm{~nm}$ ta-C followed by the deposition of $1 \mathrm{~nm}$ Fe and $0.1 \mathrm{~nm} \mathrm{Cu}$. CNT growth was carried out for $10 \mathrm{~min}$ in the temperature range of $400-750{ }^{\circ} \mathrm{C}$ using $\mathrm{C}_{2} \mathrm{H}_{2}$ carbon precursor. Nevertheless, the CNT nucleation was observed at $450{ }^{\circ} \mathrm{C}$ (Fig. $6 \mathrm{~d}$, e), the full coverage and repeatable growth on ta-C support occurred above $500{ }^{\circ} \mathrm{C}$. However, the CNT growth did occur at $450{ }^{\circ} \mathrm{C}$ when $\mathrm{Al}_{2} \mathrm{O}_{3}$ support for $\mathrm{Fe}-\mathrm{Cu}$ catalyst system was used (Fig. 6f). The CNTs were tangled with lengths only up to a few microns. The structural quality of CNTs was not judged in this study [119].

Magrez et al. demonstrated a low temperature $\left(400{ }^{\circ} \mathrm{C}\right) \mathrm{CNT}$ growth process which involves oxidative dehydrogenation reaction between $\mathrm{C}_{2} \mathrm{H}_{2}$ and $\mathrm{CO}_{2}$ [120]. They reported that this process improves the CNT growth significantly by allowing decomposition of the carbon precursors at lower temperatures and enhancing the catalytic activity without a need of extensive catalyst pre-treatment. They demonstrated the CNT growth on a range of unconventional substrates such as bulk $\mathrm{Cu}$, organic materials, carbon, glass, aluminum foil and toothpick. They adopted two catalyst systems; 1) powdered catalyst by the co-precipitation of $\mathrm{Fe}$ and Co salts on the surface of support particles and 2) e-beam evaporated $\mathrm{Fe}$ catalyst for patterned CNT growth. However, the growth below $400{ }^{\circ} \mathrm{C}$ is not mentioned clearly for e-beam evaporated Fe catalyst film where prolonged catalyst pre-treatment at relatively higher temperature is generally required for the formation of rightly sized catalyst nanoparticles. The CNT growth was conducted in a quartz tube furnace in the temperature range of $400-650{ }^{\circ} \mathrm{C}$ at ambient pressure where a $\mathrm{C}_{2} \mathrm{H}_{2} / \mathrm{CO}_{2}$ mixture (with a 1:1 stoichiometry) was used as carbon precursor. Fig. 7a shows a representative SEM image of CNTs produced by the oxidative dehydrogenation reaction of $\mathrm{C}_{2} \mathrm{H}_{2}$ with $\mathrm{CO}_{2}$ on a carbide support and Fig. $7 \mathrm{~b}$ shows a high resolution TEM image where well-structured walls of a MWCNT can be observed. Fig. 7c demonstrates the capability of this low temperature growth process by allowing CNT growth on aluminum cooking foil without melting it.

Growth of CNTs catalyzed by $\mathrm{Fe}_{2} \mathrm{Co}$ system supported by $\mathrm{Nb}_{2} \mathrm{O}_{5}$ was studied in the temperature range of $400-600{ }^{\circ} \mathrm{C}$ where the maximum production yield was obtained at $500{ }^{\circ} \mathrm{C}$ (Fig. 7d) [120]. They proposed two reaction mechanisms between $\mathrm{C}_{2} \mathrm{H}_{2}$ and $\mathrm{CO}_{2}$ :

$$
\begin{aligned}
& \mathrm{C}_{2} \mathrm{H}_{2}+\mathrm{CO}_{2} \longrightarrow 2 \mathrm{C}+\mathrm{H}_{2} \mathrm{O}+\mathrm{CO} \\
& \mathrm{C}_{2} \mathrm{H}_{2}+\mathrm{CO}_{2} \longrightarrow \mathrm{C}+2 \mathrm{CO}+\mathrm{H}_{2}
\end{aligned}
$$
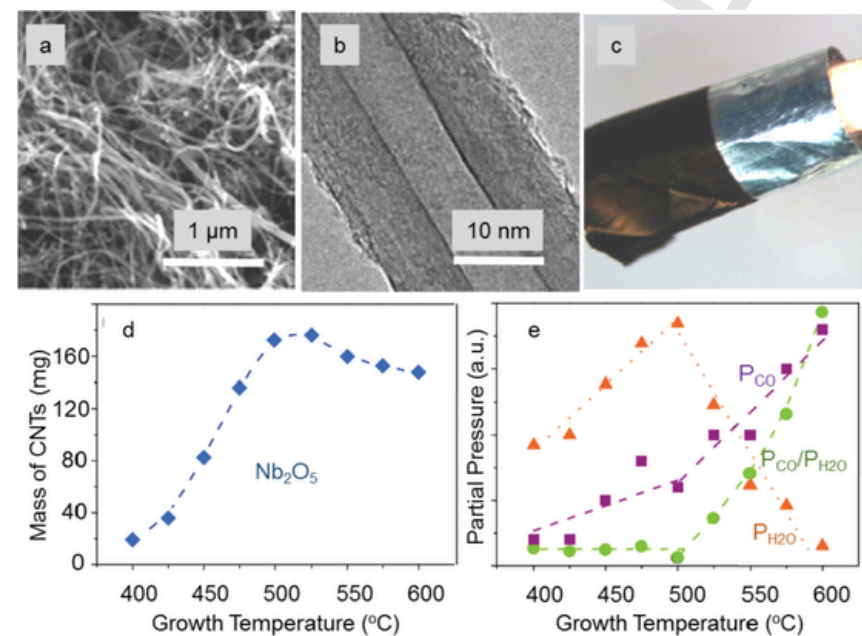

Fig. 7. (a) SEM image of CNTs grown on $\mathrm{Fe}_{2} \mathrm{Co}$ alloy supported by carbide, (b) High resolution TEM image showing well-structured MWCNT, (c) CNTs grown (black area) on Aluminum cooking foil. (d) Mass of CNTs produced using $\mathrm{Fe}_{2} \mathrm{Co}$ system supported by $\mathrm{Nb}_{2} \mathrm{O}_{5}$ as a function of growth temperature. (e) Residual gas composition analysis as a function of growth temperature. (Reprinted with permission from Ref. [120]. Copyright 2010 American Chemical Society). (A colour version of this figure can be viewed online.)
The first reaction is associated with the oxidative dehydrogenation reaction of $\mathrm{C}_{2} \mathrm{H}_{2}$ with $\mathrm{CO}_{2}$ which takes place below $500{ }^{\circ} \mathrm{C}$ as evidenced by the quantity of water produced in the residual gas composition analysis (Fig. 7e), whereas the second reaction is preferred above $500{ }^{\circ} \mathrm{C}$. In the first reaction, double the quantity of carbon radicals are produced along with water which is associated with the enhanced production of CNTs at lower temperatures. Recently, Li et al. introduced the use of common sodium-based compounds such as table salt (NaCl), baking soda $\left(\mathrm{NaHCO}_{3}\right)$, washing soda $\left(\mathrm{Na}_{2} \mathrm{CO}_{3}\right)$, and lye $(\mathrm{NaOH})$, where $\mathrm{Na}$ acts as a catalyst in atmospheric thermal CVD growth of CNTs [121]. They utilized the oxidative dehydrogenation reaction between $\mathrm{C}_{2} \mathrm{H}_{2}$ and $\mathrm{CO}_{2}$ to demonstrate $\mathrm{CNT}$ growth below $400{ }^{\circ} \mathrm{C}$ on a range of substrates including Carbon fibers, Alumina fibers, $\mathrm{Si}$ wafers and Ti sheets.

Liu et al. used Ni-P-Pd catalyst system to achieve CNT growth at a minimum of $400{ }^{\circ} \mathrm{C}$ [122]. They utilized an electroless non-isothermal deposition (NITD) technique $[123,124]$ to deposit Ni-P particles onto a Si substrate (Fig. 8a) using the plating solution of $\mathrm{NiSO}_{4} \cdot 6 \mathrm{H}_{2} \mathrm{O}$, $\mathrm{NaH}_{2} \mathrm{PO}_{2} \cdot \mathrm{H}_{2} \mathrm{O}, \mathrm{C}_{2} \mathrm{H}_{5} \mathrm{O}_{2} \mathrm{~N}, \mathrm{C}_{3} \mathrm{H}_{5} \mathrm{O}_{3} \mathrm{Na}(100 \mathrm{ml})$ and then $\mathrm{PdCl}_{2}$ solution to prepare Ni-P-Pd co-catalyst system. The main feature of the NITD technique is that the temperature of the plated substrates can be taken up to $140{ }^{\circ} \mathrm{C}$ to enhance the reaction rate, while the stability of the solution is maintained by keeping its temperature below $60{ }^{\circ} \mathrm{C}$ through the use of a water-based cooling system [123]. The CNTs were grown by TCVD in the temperature range of $400-600{ }^{\circ} \mathrm{C}$ using $\mathrm{C}_{2} \mathrm{H}_{2}$ gas as carbon feedstock. An SEM image of the CNTs grown at $400{ }^{\circ} \mathrm{C}$ is shown in Fig. $8 \mathrm{~b}$, where low density tangled CNTs with other carbonaceous products can be observed. The length of the CNTs is around $5 \mu \mathrm{m}$ with no vertical alignment and poor structural quality even when grown at $500{ }^{\circ} \mathrm{C}$ as can be seen in the TEM image shown in the paper. The low temperature growth of CNTs at $400{ }^{\circ} \mathrm{C}$ was observed only for Ni-P-Pd system, whereas CNT growth on Ni-P catalyst occurs only above $500{ }^{\circ} \mathrm{C}$. The change in catalyst particle morphology after Pd deposition and ability of Pd to enhance catalytic activity by promoting $\mathrm{C}_{2} \mathrm{H}_{2}$ decomposition is considered to be the promoter of the process [122].

Nessim et al. presented an engineering solution to achieve low temperature growth of carbon nanotubes by enabling thermal decomposition of ethylene at higher temperature than the substrate temperature [114]. They evaporated $2 \mathrm{~nm}$ Fe as a catalyst on a metallic layer stack of $\mathrm{Ta} / \mathrm{Cu} / \mathrm{Ta}$ deposited on $\mathrm{S} / \mathrm{SiO}_{2}$ substrate and conducted CNT growth in a three-zone furnace using $\mathrm{C}_{2} \mathrm{H}_{4}$ as carbon precursor at atmospheric pressure (Fig. 8c). They used a 'fast heating' technique where the sample remained at room temperature outside the growth zone (zone 3) until the furnace reaches the desired temperature, after which hydrogen and ethylene were introduced and the sample moved to zone 3 . The zone 3 temperature was set constant at $470{ }^{\circ} \mathrm{C}$, whereas the temperature of first two zones (gas preheating) was varied from 650 to $770{ }^{\circ} \mathrm{C}$, which also caused the zone 3 temperature to rise up to $500{ }^{\circ} \mathrm{C}$. Vertically aligned forest of CNTs was achieved in the wide range of gas preheating temperatures. Fig. 8d shows an SEM image of CNTs grown for $45 \mathrm{~min}$ at a substrate temperature of $500{ }^{\circ} \mathrm{C}$ and a gas preheating temperature of $770{ }^{\circ} \mathrm{C}$. The TEM analysis showed crystalline MWCNTs with some amorphous carbon deposited on the outer walls [114].

Tsai et al. studied the CNT growth on Ti-Co catalyst and were able to demonstrate the growth on a glass substrate in the temperature range of $450-550{ }^{\circ} \mathrm{C}$ [125]. They sputtered $\mathrm{Ti}$ and $\mathrm{Co}$ in a layered form $(0.1-10 \mathrm{~nm})$ and in hybrid form where both materials were sputtered simultaneously. The composition of the hybrid form was controlled by adjusting the DC power supplied to the target electrodes. The CNT growth was conducted in a cold-wall rapid heating and cooling CVD chamber using $\mathrm{C}_{2} \mathrm{H}_{2}$ gas. It is found that $\mathrm{Ti} / \mathrm{Co}$ composites $(0.5 / 0.5 \mathrm{~nm}$ and $0.6 /$ $1.0 \mathrm{~nm}$ ) corresponding to $\mathrm{Ti}$ atomic fractions of $38 \%$ and $48 \%$ produced vertically aligned CNTs of lengths ranging from 0.5 to $5 \mu$ 

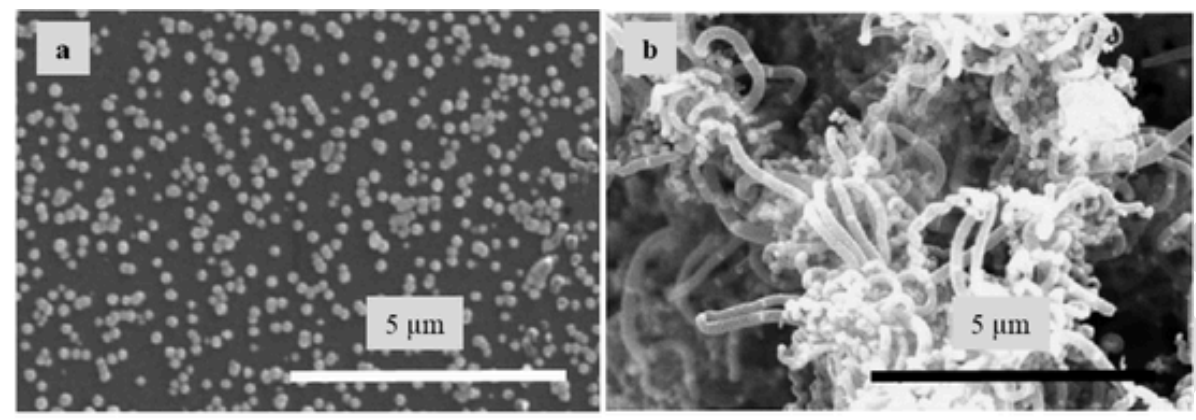

c

d
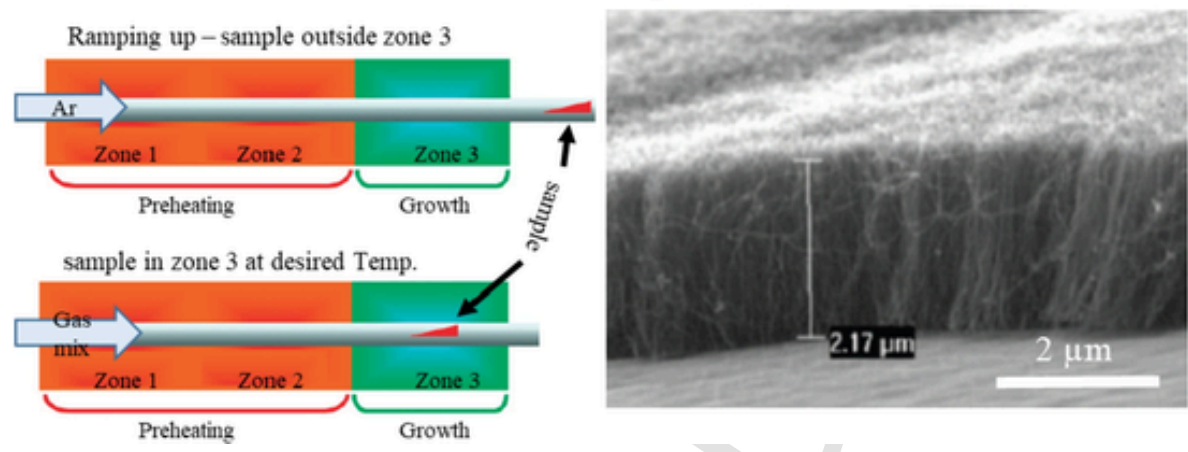

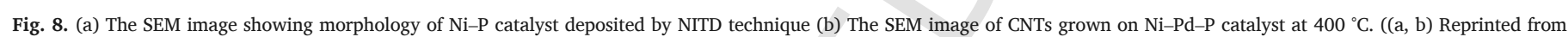

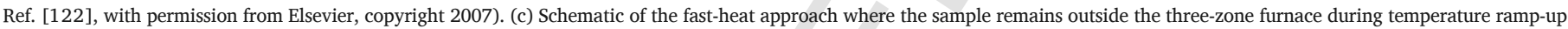

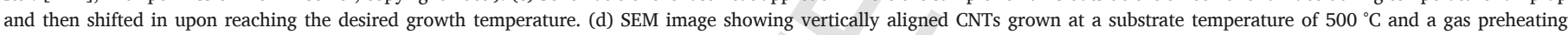
temperature of $770{ }^{\circ} \mathrm{C}$. ((c, d) Reprinted with permission from Ref. [114]. Copyright 2009 American Chemical Society). (A colour version of this figure can be viewed online.)

$\mathrm{m}$ in the whole temperature range, whereas no growth was observed for the third composite corresponding to Ti fraction of $78 \%$. Similarly, no CNT growth was observed when only Co was used which shows that $\mathrm{Ti}$ plays an important role in the growth of CNTs [125]. Goichi et al. optimized $\mathrm{Ti}(0.5 \mathrm{~nm}) / \mathrm{Co}(0.5 \mathrm{~nm})$ thickness and studied the effect of preheating the $\mathrm{C}_{2} \mathrm{H}_{2}$ at $700{ }^{\circ} \mathrm{C}$ in a two-zone furnace. The CNT growth was conducted with and without gas preheating in the temperature range of $450-550{ }^{\circ} \mathrm{C}$ [126]. Vertically aligned CNTs were achieved in both cases with lengths slightly greater for gas preheated samples (Fig. 9a, b). Similarly, the quality of the CNTs grown with gas preheating was found slightly better $\left(\mathrm{I}_{\mathrm{D}} / \mathrm{I}_{\mathrm{G}}: 0.79-0.85\right)$ than those grown without gas preheating $\left(\mathrm{I}_{\mathrm{D}} / \mathrm{I}_{\mathrm{G}}: 0.93-1.04\right)$ as judged by Raman spectra analysis [126].

Sugime et al. reported high density CNT growth at $450{ }^{\circ} \mathrm{C}$ on sputtered Mo $(0.8 \mathrm{~nm}) / \mathrm{Co}(2.5 \mathrm{~nm})$ co-catalyst system deposited on $\mathrm{Ti} / \mathrm{Cu}$ metallic layers coated on Si substrate [127]. The CNT growth was conducted in a cold wall CVD chamber using $\mathrm{C}_{2} \mathrm{H}_{2}$ for $3 \mathrm{~min}$ in the temperature range of $400-550{ }^{\circ} \mathrm{C}$. For comparison, CNT growth was also conducted using only Co catalyst, that is, without Mo. The height of the CNTs with Mo was $0.38 \mu \mathrm{m}$ (Fig. 9c), whereas without Mo was $0.83 \mu \mathrm{m}$. The mass density of the as-grown CNTs was significantly increased from $0.38 \mathrm{gcm}^{-3}$ (without Mo) to $1.6 \mathrm{gcm}^{-3}$ with Mo, indicating a significant role of Mo in achieving the high density of CNTs which is important to enable a high conductivity within the CNT bundles. The areal density of CNTs grown with Mo was $5.5 \times 10^{11} \mathrm{~cm}^{-2}$ with average diameter of $13 \pm 1.3 \mathrm{~nm}$ and the corresponding wall density was $7.8 \times 10^{12} \mathrm{~cm}^{-2}$ with 14 average number of walls per tube. Based on their TEM, AFM and XPS analysis they concluded that Mo causes root-growth of CNTs by alloying with Ti which prevents Co diffusion and produces uniformly sized distribution of stabilized Co particles. The uniformly sized and stabilized Co nanoparticles results in a considerably higher yield of CNT growth as illustrated in Fig. 9d, e. In a later report, the same group used $0.5 \mathrm{~nm} \mathrm{Al} \mathrm{film} \mathrm{as} \mathrm{a} \mathrm{partial}$ barrier layer between Co and Mo to grow high density $\left(1.2 \mathrm{gcm}^{-3}\right)$ vertically aligned CNTs on $\mathrm{Cu}$ support at $450{ }^{\circ} \mathrm{C}$ [128]. The major
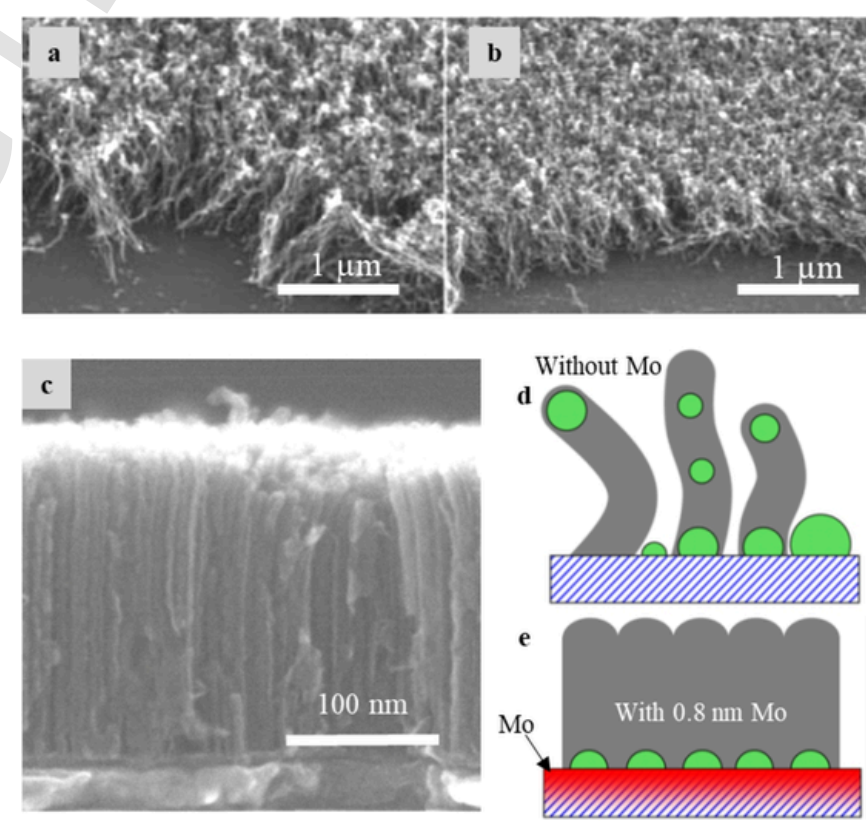

Fig. 9. SEM images of CNTs grown at $450{ }^{\circ} \mathrm{C}$ : (a) with gas preheated at $700{ }^{\circ} \mathrm{C}$. (b) without gas preheating. ((a, b) Reprinted with permission from Ref. [126]. Copyright 2005 The Japan Society of Applied Physics). (c) SEM image of high density CNTs grown using Mo $(0.8 \mathrm{~nm}) / \mathrm{Co}$. (d, e) Illustration of the catalyst particle formation and subsequent CNT growth with and without Mo, respectively. ((c-e) Reprinted from Ref. [129], with the permission of AIP Publishing). (A colour version of this figure can be viewed online.)

difference caused by the use of $\mathrm{Al}$ film is the decrease in the inner diameters of the MWCNTs, resulting in a high number of average walls per tube (31) and a wall-density of $4.1 \times 10^{12} \mathrm{~cm}^{-2}$. The Al layer serves to reduce the interaction between Co and Mo, prevents interdiffusion and enhances the reduction of Co to metallic state. 
Nuri et al. focused on catalyst deposition conditions in order to grow high density vertically aligned carbon nanotubes on a conductive support at $400{ }^{\circ} \mathrm{C}$ [130]. They carried out sputter deposition of the catalyst at various conditions which include the deposition at room temperature and at $400{ }^{\circ} \mathrm{C}$ using high and low deposition rates and substrate bias. They concluded that a moderate density of the catalyst nanoparticles is required to achieve high areal wall density of CNTs as the catalyst nanoparticles aggregate during the CVD process if their density is too high, as schematically shown in Fig. 10a. To achieve the optimum high density $\left(2.8 \times 10^{12} \mathrm{~cm}^{-2}\right)$ of the catalyst nanoparticles, they deposited $0.6 \mathrm{~nm} \mathrm{Ni}$ on $5 \mathrm{~nm}$ TiN film at $400{ }^{\circ} \mathrm{C}$ using $8.1 \mathrm{pms}^{-1}$ (particulate matter per second) deposition rate and a substrate bias of $-20 \mathrm{~V}$. On a heated substrate, catalyst adatoms diffuse over the surface and attach to each other to form nanoparticles. After performing catalyst pre-treatment at $400{ }^{\circ} \mathrm{C}$ in a $\mathrm{H}_{2}$ environment for $8 \mathrm{~min}$ in a quartz tube CVD reactor, the CNT growth was conducted using $180 \mathrm{sccm} \mathrm{C}_{2} \mathrm{H}_{2}$ at $0.27 \mathrm{kPa}$ ( $\sim 2$ Torr). They reported vertically aligned growth of MWCNTs (Fig. $10 \mathrm{~b}$ ) with mass density as high as $1.1 \mathrm{gcm}^{-3}$ and areal wall density as high as $1.2 \times 10^{13} \mathrm{~cm}^{-2}$ considering 8 walls per tube. They also noted that a low partial pressure of $\mathrm{C}_{2} \mathrm{H}_{2}(0.13-1.3 \mathrm{~Pa})$ is required to keep the catalyst activated for a prolonged CNT growth when low temperatures are used. No Raman analysis is presented in this report to estimate the structural quality of the CNTs, however the TEM images show distinct concentric walls of individual MWCNTs.

Haider et al. demonstrated low temperature growth of CNTs on alumina supported $\mathrm{Fe}$ and $\mathrm{Fe}-\mathrm{Cu}$ catalyst sputtered on $\mathrm{Si}$ substrate using waste gas mixture achieved in the Fischer-Tropsch process [131]. In the Fischer-Tropsch process $\mathrm{CO}$ and $\mathrm{H}_{2}$ are catalytically converted into liquid hydrocarbons in the temperature range of $150-300{ }^{\circ} \mathrm{C}$. The stated composition of the waste gas mixture is $\mathrm{CH}_{4}(30 \%), \mathrm{C}_{2} \mathrm{H}_{6}(8 \%)$, $\mathrm{C}_{2} \mathrm{H}_{4}(6 \%), \mathrm{C}_{3} \mathrm{H}_{8}(5 \%), \mathrm{C}_{3} \mathrm{H}_{6}(2 \%), \mathrm{H}_{2}(40 \%), \mathrm{CO}(5 \%)$, and $\mathrm{N}_{2}(4 \%)$. Apart from utilizing the waste products, other potential benefits include low cost, low temperature thermal decomposition in the presence of unsaturated hydrocarbons with low energy covalent bonds and increased catalyst life of up to 75 min which may have resulted from the removal of amorphous carbon by the water vapors formed during the decomposition reaction, in a similar phenomenon proposed for the 'super growth' [51].

The CNT growth was conducted in a thermal CVD system at atmospheric pressure where the catalyst was heated in $\mathrm{H}_{2}$ environment for 10 min before initiating the growth by introducing the carbonaceous gas mixture in the reaction chamber for various time durations (10-60 min). Vertically aligned growth of high density CNTs was observed in the entire temperature range $\left(400-550{ }^{\circ} \mathrm{C}\right)$ with increased growth rate at higher temperatures (Fig. 10c, d). The reported Raman $\mathrm{I}_{\mathrm{D}} / \mathrm{I}_{\mathrm{G}}$ ratio indicate better structural quality at higher temperatures and increased defects at lower temperatures [131].

Vollebregt et al. reported CNT growth on Ti/TiN conductive support deposited on a $\mathrm{Si}$ substrate for interconnect vias in the temperature range of $350-500{ }^{\circ} \mathrm{C}$, using $5 \mathrm{~nm}$ Co or $3 \mathrm{~nm}$ of Co-Al as catalyst $[132,133]$. The growth was conducted in a CVD reactor using a mixture of $\mathrm{C}_{2} \mathrm{H}_{2} / \mathrm{H}_{2}(50 / 700 \mathrm{sccm})$ at $80 \mathrm{mbar}$ pressure [133]. Vertically aligned growth of CNTs with $1.5 \mu \mathrm{m}$ length and $5 \times 10^{10} \mathrm{~cm}^{-2}$ density at $350{ }^{\circ} \mathrm{C}$ is reported. The Raman $\mathrm{I}_{\mathrm{D}} / \mathrm{I}_{\mathrm{G}}$ values of the CNTs grown in the above temperature range are given as $1.09-1.26$ and $1.22-1.49$ for Co and $\mathrm{Co}-\mathrm{Al}$ catalyst systems, respectively [133].

Chuang et al. used chemical bath deposition method to grow $\mathrm{Ni}(\mathrm{OH})_{2}$ film on fluorine-doped tin oxide (FTO) substrate, which was reduced to Ni catalyst during the CNT growth process conducted for $2 \mathrm{~s}$ at $400{ }^{\circ} \mathrm{C}$ in a tube furnace using a mixture of $\mathrm{C}_{2} \mathrm{H}_{2}$ and $\mathrm{Ar}$ at 20 torr pressure [134]. The as-grown CNTs are hard to detect by XRD, however Raman spectroscopy, SEM and TEM confirm the formation of CNTs around the Ni particles. The as-grown CNTs were utilized as counter electrode for dye-sensitized solar cells.

Jin et al. introduced a novel route of achieving low-temperature synthesis of functional CNT-transition metal oxide nanocomposites
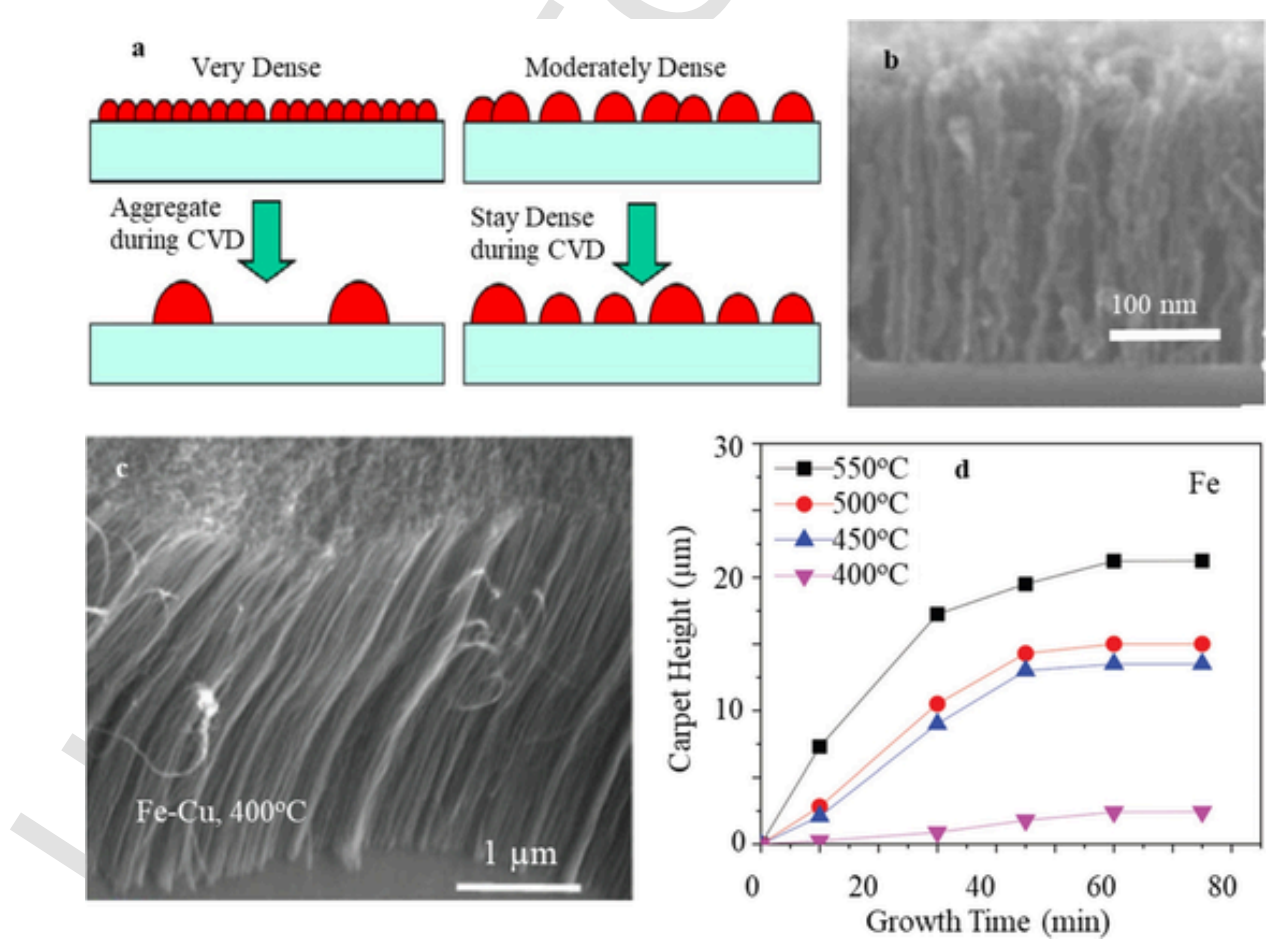

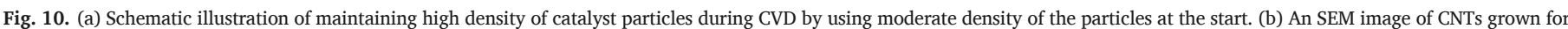

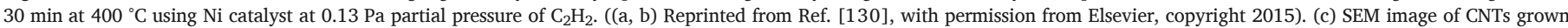

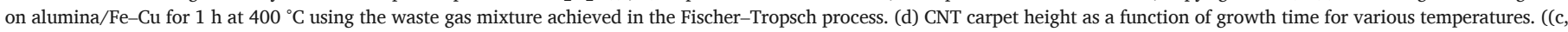

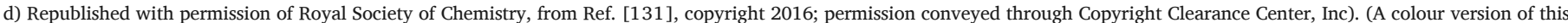
figure can be viewed online.) 
at low temperatures of $400-500{ }^{\circ} \mathrm{C}$ using a mixture of $\mathrm{C}_{2} \mathrm{H}_{2} / \mathrm{Ar}$ in a tube furnace [135]. They employed a range of manganese oxides with different morphologies and structures and found that only 2D nanosheets of layered $\mathrm{MnO}_{2}$ act as efficient catalyst for the CNT growth, which they attributed to the larger surface area of the sheets allowing enhanced carbon deposition. The demonstrated the use of grown material (CNT-metal oxide composites) as lithium-ion battery electrode.

Zhang et al. used microwave-assisted CVD to grow CNTs on pin net shell (PNS) chars as renewable substrate [136]. The PNS was crushed to get particle size of $60-200 \mu \mathrm{m}$ and processed with nickel nitrate solution to impregnate the Ni catalyst with the PNS particles, which involves thermal annealing at $600{ }^{\circ} \mathrm{C}$, making this process un-suitable for temperature sensitive substrates. CNT growth was conducted using $\mathrm{CH}_{4}$ gas as carbon feedstock in the temperature range of $400-700{ }^{\circ} \mathrm{C}$ for $60 \mathrm{~min}$ in a quartz reactor connected with a microwave oven of $2 \mathrm{~kW}$ output power. The CNT growth at $400{ }^{\circ} \mathrm{C}$ is difficult to observe in the SEM images shown in the report, however it improves for the higher temperatures with $600{ }^{\circ} \mathrm{C}$ as optimum value.

\subsection{CNT growth using plasma enhanced CVD}

PECVD is mainly used to facilitate decomposition of carbon feedstock at lower temperatures. Awano et al. published a series of papers in order to achieve low temperature CNT growth for interconnect via application (Fig. 11a-c), using initially TCVD and then PECVD [100,137-144]. In one report they used $2.5 \mathrm{~nm}$ Co film as a catalyst to grow $\sim 500 \mathrm{~nm}$ vertically aligned MWCNTs in $40 \mathrm{~min}$ in lithographically patterned via holes of $2 \mu \mathrm{m}$ diameter at $450{ }^{\circ} \mathrm{C}$ using $\mathrm{C}_{2} \mathrm{H}_{2}$ on $\mathrm{Cu} / \mathrm{Ta} / \mathrm{Ti}$ based metallic support [137]. Following this, they reported a size classified pre-formed catalyst particle approach to grow CNT arrays at $420{ }^{\circ} \mathrm{C}$ using $\mathrm{C}_{2} \mathrm{H}_{2}$ in their hot-filament CVD system [138]. For the size classification, they generated Co particles by laser ablation and accelerated them with a carrier gas through a nozzle to an impaction plate. Particles with higher inertia were collected by the plate whereas remaining were brought downstream with the carrier gas and deposited on a Si substrate [144]. They further reported

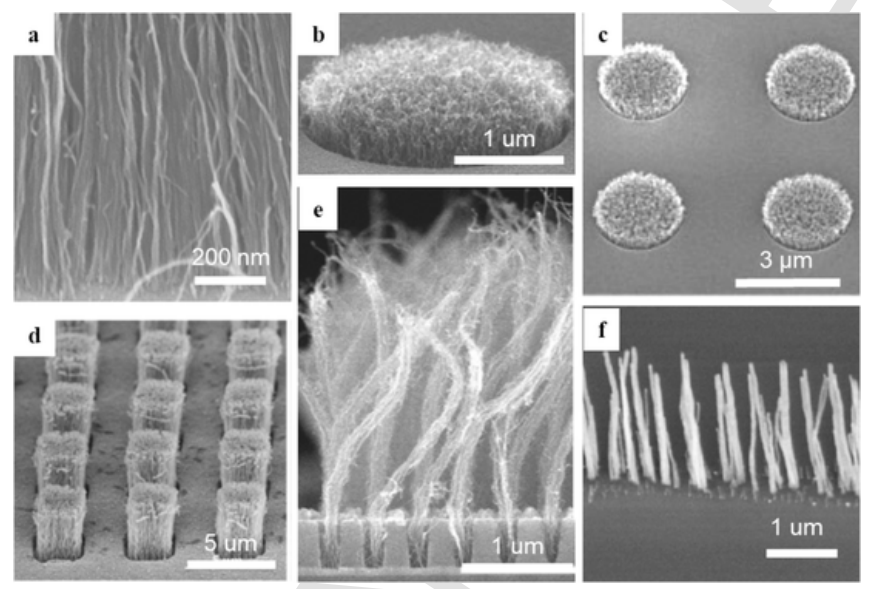

Fig. 11. PECVD grown CNTs: (a) Dense CNT growth at $450{ }^{\circ} \mathrm{C}$ (reprinted with permission from Ref. [145], (c2010 The Japan Society of Applied Physics). (b) CNT growth in a $2 \mu \mathrm{m}$ diameter via hole at $450{ }^{\circ} \mathrm{C}$ (reprinted from [100], with the permission of AIP Publishing). (c) CNTs grown selectively in via holes by surface-wave plasma enhanced CVD on size-classified catalyst nanoparticles at $430{ }^{\circ} \mathrm{C}$ (reprinted with permission from Ref. [143], Copyright 2008 The Japan Society of Applied Physics). (d) CNTs grown in $3 \mu \mathrm{m}$ via holes using $\mathrm{Ni} / \mathrm{Al} / \mathrm{Ni}$ multilayer catalyst at $420{ }^{\circ} \mathrm{C}$ (republished with permission of Royal Society of Chemistry, from Ref. [146], copyright 2018; permission conveyed through Copyright Clearance Center, Inc.). (e) CNT growth at $540{ }^{\circ} \mathrm{C}$ in $180 \mathrm{~nm}$ via holes (reprinted from Ref. [103], Copyright (2013), with permission from Elsevier). (f) Carbon nanofibers grown from e-beam patterned Ni catalyst at $500{ }^{\circ} \mathrm{C}$ (Reprinted from Ref. [147], with the permission of AIP Publishing). (A colour version of this figure can be viewed online.) the growth of $\mathrm{CNTs}$ at $390{ }^{\circ} \mathrm{C}$ on $\mathrm{Cu} / \mathrm{Ta} / \mathrm{Ti}$ support using the size-classified Co particles in a remote microwave plasma CVD method $[100,139]$. In this method, a spherical plasma of $10-20 \mathrm{~mm}$ diameter was generated by applying $60 \mathrm{~W}$ microwave power $(2.4 \mathrm{GHz})$ at the edge of an antenna in the CVD chamber where a mixture of $\mathrm{CH}_{4}$ and $\mathrm{H}_{2}$ was introduced for CNT growth. It is called 'remote plasma' because the substrate was kept $50 \mathrm{~mm}$ away from the plasma sphere to avoid plasma-based damage to the CNTs. In order to further minimize this damage, a quartz ion trap and an electrically grounded metal mesh plate was introduced above the sample stage [143]. Later, in order to improve the quality of CNTs, they used 'pulsed excited remote plasma CVD' and a biased plate type electrode near the sample stage [141]. A gas mixture of $\mathrm{CH}_{4}$ and $\mathrm{H}_{2}$ was used for the CNT growth and the plasma was generated at $70 \mathrm{~mm}$ away from the sample stage, between a $110 \mathrm{~mm}$ diameter shower-type upper electrode with gas inlet and a lower electrode with a $10 \mathrm{~mm}$ aperture in its central region, using $\pm 700 \mathrm{~V}, 8 \mathrm{kHz}$ pulse frequency and $0.8 \mu$ s pulse width. To reduce the number of charged particles and radicals, they added a load resistor $(1-10 \mathrm{k} \Omega$ ) in series which reduced the plasma power from tens of watts to $1-10 \mathrm{~W}$. A biased plate-type screening electrode was introduced $10 \mathrm{~mm}$ above the sample stage to block and repel the charged particles. The CNTs grown with this method at $400{ }^{\circ} \mathrm{C}$ on Co nanoparticles deposited on $\mathrm{Si} / \mathrm{SiO}_{2} / \mathrm{TiN}$ using the impactor method, were reported to exhibit higher growth rates $(0.98 \mu \mathrm{m} / \mathrm{min})$ and better structural quality as judged by the TEM analysis. In order to achieve higher density of CNTs at low temperatures $\left(450{ }^{\circ} \mathrm{C}\right)$, they reported a three step process in which they deposited a $1.7 \mathrm{~nm}$ Co catalyst film on a Si substrate with 70-200 nm diameter vias patterned on TaN/Cu/TaN/TiN line structure [145]. To achieve high density of the catalyst nanoparticles, they utilized plasma-induced nanoparticle formation at relatively lower temperatures $\left(25-260^{\circ} \mathrm{C}\right)$ in order to prevent aggregation of the catalyst particles. They used a pulse-excited CVD system equipped with a biased plate type screening electrode and a shower-type upper electrode capable of switching plasma between remote and exposure modes. In the second step, they immobilized the nanoparticles by encapsulating them with graphitic carbon using a mixture of $\mathrm{CH}_{4} / \mathrm{H}_{2}$ in the temperature range of $170-350{ }^{\circ} \mathrm{C}$. Finally, the CNT growth was conducted using $\mathrm{CH}_{4} / \mathrm{H}_{2}$ gas mixture and low-power remote plasma in the temperature range of $450-600{ }^{\circ} \mathrm{C}$. The CNT areal density of $1 \times 10^{12} \mathrm{~cm}^{-2}$ and occupancy of $30-40 \%$ was reported [145].

$\mathrm{Li}$ et al. used $\mathrm{Ni} / \mathrm{Al} / \mathrm{Ni}$ catalyst system to enable low temperature $\left(350^{\circ} \mathrm{C}\right)$ PECVD growth of dense and vertically aligned CNTs on a conductive titanium silicide substrate (Fig. 11d) $[146,148]$. The Al layer sandwiched between two Ni layers inhibits Ni diffusion into silicide and immobilizes the Ni catalyst on the substrate during nanoparticle formation due to the interaction with the adjacent Ni layers. CNT growth was conducted in a PECVD system (Seki Technotron Corp. AX5200 M) where the samples were annealed first for $10 \mathrm{~min}$ in a $\mathrm{H}_{2}: \mathrm{N}_{2}$ mixture (3:1) at 2.8 Torr and then growth was carried out using $35 \mathrm{sccm}$ of $\mathrm{CH}_{4}$ and $200 \mathrm{~W}$ plasma power [148]. The growth rate of the CNTs grown at $350{ }^{\circ} \mathrm{C}$ was $120 \mathrm{~nm}-\mathrm{min}^{-1}$ and the grown CNTs were vertical aligned with an average diameter of $20 \mathrm{~nm}$.

Chiodarelli et al. also performed low temperature PECVD growth of CNTs for interconnect vias (Fig. 11e), as reported in some of their publications [103,149-152]. They deposited $1.5 \mathrm{~nm}$ Ni layer as a catalyst in an array of 150-300 nm diameter holes etched into a stack of $80 \mathrm{~nm}$ $\mathrm{SiC}, 300 \mathrm{~nm}$ phosphorous doped $\mathrm{SiO}_{2}$ and $30 \mathrm{~nm} \mathrm{SiC} \mathrm{deposited} \mathrm{over}$ a TiN layer (i.e. TiN $/ \mathrm{SiC} / \mathrm{SiO}_{2} / \mathrm{SiC}$ ) $[149,150]$. CNT growth was performed in a microwave remote-plasma reactor at temperatures $470{ }^{\circ} \mathrm{C}$ and $400{ }^{\circ} \mathrm{C}$, using a gas mixture of $\mathrm{C}_{2} \mathrm{H}_{4}, \mathrm{H}_{2}$ and Ar. The CNTs grown at $470{ }^{\circ} \mathrm{C}$ were found to have length $1.3 \mu \mathrm{m}$, diameter $8.3 \mathrm{~nm}$ and density $2 \times 10^{11} \mathrm{~cm}^{-2}$, whereas the same parameters for the CNTs grown at $400{ }^{\circ} \mathrm{C}$ were found to be $0.52 \mu \mathrm{m}, 12.1 \mathrm{~nm}$ and $2 \times 10^{11} \mathrm{~cm}^{-2}$, respectively. 
Baro et al. utilized pulsed PECVD to grow vertically aligned CNTs in the temperature range of $350-490{ }^{\circ} \mathrm{C}$ using $50 \mathrm{~W}$ pulse power and a mixture of $\mathrm{H}_{2} / \mathrm{CH}_{4}(80 / 100)$ at 10 Torr pressure [153]. To achieve the low temperature growth, they optimized $\mathrm{Ni}$ catalyst film thickness to be $30 \mathrm{~nm}$, sputtered at 0.5 Torr pressure on Si substrate with $\mathrm{Al}_{2} \mathrm{O}_{3}$ as base layer and Mo as top layer $\left(\mathrm{Si} / \mathrm{Al}_{2} \mathrm{O}_{3} / \mathrm{Ni} / \mathrm{Mo}\right)$. The grown CNTs are less than a micron in length with their diameter $\sim 43 \mathrm{~nm}$ and a poor structural quality, as inferred from Raman spectroscopy and TEM analysis.

Chen et al. reported growth of vertically aligned MWCNTs below $330{ }^{\circ} \mathrm{C}$ on n-Si substrate with $10 \mathrm{~nm}$ sputtered Fe film as a catalyst, using a mixture of $\mathrm{CH}_{4} / \mathrm{CO}_{2}$ gases in a microwave plasma CVD system [154]. They studied the effect of $\mathrm{CH}_{4} / \mathrm{CO}_{2}$ ratio in the temperature range of $300-350{ }^{\circ} \mathrm{C}$ (monitored by a pyrometer) using $250-300 \mathrm{~W}$ microwave power with DC bias from -150 to $-200 \mathrm{~V}$ and the process pressure of 1.3-2.0 $\mathrm{kPa}$. The optimum $\mathrm{CH}_{4} / \mathrm{CO}_{2}$ ratio was found to be 29.5/ $30 \mathrm{sccm}$ whereas no CNT growth observed for $\mathrm{CH}_{4}$ contents below 25 sccm. Similarly, decreasing $\mathrm{CO}_{2}$ to $25-20 \mathrm{sccm}$ while keeping $\mathrm{CH}_{4}$ at 30 sccm also resulted in no CNT growth. The CNTs grown for 20 min under optimized conditions exhibit vertical alignment with lengths up to $5 \mu \mathrm{m}$, as observed in the SEM images. The TEM analysis shows graphitized walls of MWCNTs with periodic compartments in their structure and their diameter ranging from 15 to $20 \mathrm{~nm}$. Raman spectrum taken using $514 \mathrm{~nm}$ laser wavelength shows higher D-peak than the G-peak, indicating high structural defects in the tubes. Roy et al. also used $\mathrm{CO}_{2}$ with $\mathrm{CH}_{4}$ for the $\mathrm{CNT}$ growth at $300{ }^{\circ} \mathrm{C}$ in a microwave-plasma enhanced CVD system, however they used high catalyst (Fe) annealing temperature $\left(650-800{ }^{\circ} \mathrm{C}\right)$, which renders their process unsuitable for CNT growth on temperature sensitive substrates $[155,156]$.

Li et al. demonstrated CNT growth on conductive Ti silicide substrate at temperature as low as $350{ }^{\circ} \mathrm{C}$ in a PECVD system using a catalyst layer stack of $\mathrm{Ni} / \mathrm{Al} / \mathrm{Ni}(1 / 0.5 / 1 \mathrm{~nm})$ [148]. The multilayer catalyst design with $0.5 \mathrm{~nm} \mathrm{Al}$ sandwiched between the two Ni layers of $1 \mathrm{~nm}$ thickness was found to be effective in preventing catalyst diffusion and sintering, and hence promoting CNT growth. The process was conducted using $\mathrm{CH}_{4} / \mathrm{H}_{2} / \mathrm{N}$ gas mixture at 2.8 Torr pressure with $200 \mathrm{~W}$ plasma power, which resulted in the growth of vertically aligned CNTs at a rate of $120 \mathrm{~nm} / \mathrm{min}$. Recently, Xiao et al. from the same group reported high density vertically aligned growth of MWCNTs on insulating surface $\left(\mathrm{ZrO}_{2}\right)$ at temperatures as low as $340{ }^{\circ} \mathrm{C}$, using the same catalyst system and growth conditions [157]. The $10 \mathrm{~nm} \mathrm{ZrO}_{2}$ insulating layer was deposited between the catalyst and Si substrate using atomic layer deposition, which prevents catalyst sintering because of its high surface energy $\left(1.08 \mathrm{~J} / \mathrm{m}^{2}\right)$.

$\mathrm{Ji}$ et al. developed a method to deposit the catalyst by active screen plasma and PECVD growth of CNTs in the same chamber [158]. They installed a $\mathrm{Ni}$ lid and a 316 stainless steel lid above the sample ( $\mathrm{Si}$ wafer) and connected these lids with bottom electrode. In the first step, they deposited $30 \mathrm{~nm}$ catalyst film comprising $\mathrm{Fe}, \mathrm{Ni}$ and $\mathrm{Cr}$ at $300{ }^{\circ} \mathrm{C}$ by striking plasma for $10 \mathrm{~min}$ using $500 \mathrm{~W}$ rf power and $\mathrm{Ar} /$ $\mathrm{H}_{2}$ mixture, and then they carried out CNT growth for $100 \mathrm{~min}$ in the temperature range of $400-500{ }^{\circ} \mathrm{C}$, using $\mathrm{C}_{2} \mathrm{H}_{2}$ as carbon feedstock and $30 \mathrm{~W}$ rf power. Growth of vertically aligned CNTs with lengths from 0.9 to $6.0 \mu \mathrm{m}$ is reported in this study.Mugadza et al. reported PECVD growth of MWCNTs on indium tin oxide (ITO) coated glass substrate at $200{ }^{\circ} \mathrm{C}$ and their incorporation into solar cells [159]. They prepared monometallic and bimetallic catalyst nanoparticles from the respective metal chlorides by solution process involving several steps. The metal nanoparticles were drop casted on the ITO coated glass substrate and the CNT growth was done using liquid petroleum gas in a non-equilibrium PECVD apparatus constructed by assembling commercially available components. Given the growth was conducted at $200{ }^{\circ} \mathrm{C}$, good characteristics of MWCNTs were observed with lengths in 10s of micron, vertical alignment and Raman $\mathrm{I}_{\mathrm{D}} / \mathrm{I}_{\mathrm{G}}$ ratio of 0.83 .

Hofmann et al. claimed growth of vertically aligned carbon nanofibers (CNFs) on $6 \mathrm{~nm} \mathrm{Ni}$ catalyst at $120^{\circ} \mathrm{C}$ by PECVD [147]. The samples were preheated for $15 \mathrm{~min}$ at $1.2 \mathrm{mbar}^{\mathrm{NH}_{3}}$ pressure to reach to the desired growth temperature and then the growth was conducted for $30 \mathrm{~min}$ using $\mathrm{C}_{2} \mathrm{H}_{2} / \mathrm{NH}_{3}(50 / 200 \mathrm{sccm})$ at $1.5 \mathrm{mbar}$ in the temperature range of $120-500{ }^{\circ} \mathrm{C}$. The plasma was generated by applying a fixed voltage of $600 \mathrm{~V}$ between sample stage and gas shower head, and a stable discharge current of $30 \mathrm{~mA}$ was maintained during the growth. HREM analysis showed that there was a degree of graphitization in the CNFs which decreases with decreasing the growth temperature. The grown CNFs were vertically aligned with a bamboo-like structure. The growth mechanism of the low temperature growth of CNFs was proposed where the plasma ionizes the gas and cause a local surface heating which enables the adsorption and diffusion of carbon atoms on the catalyst particles.

We demonstrated first low temperature growth of CNFs from radio-frequency plasma-enhanced CVD at room temperature [50]. It was when we started to understand the importance of 'top down heating' which later lead to the realization of low temperature PTCVD growth of CNTs. In this study, we substituted the requirement of thermal energy with plasma decomposition of methane on $\mathrm{Ni}$ catalyst for the growth of CNFs. The CNF synthesis was conducted in a radio-frequency (13.56 MHz) PECVD system at $200 \mathrm{~W}$ power and 1000 mbar process pressure of $\mathrm{CH}_{4}$ or $\mathrm{CH}_{4} / \mathrm{H}_{2}(30 / 50 \mathrm{sccm})$ using $\mathrm{Ni}$ powder catalyst placed on graphite, silicon or plastic substrates. The CNFs were produced at room temperature, $100{ }^{\circ} \mathrm{C}$ and $250{ }^{\circ} \mathrm{C}$ for the deposition times of $15-30 \mathrm{~min}$. The growth rate of CNFs is estimated to be $300 \mathrm{~nm} / \mathrm{min}$ and the statistical distribution of their diameter peaks around $50 \mathrm{~nm}$. Electron microscopy analysis reveals Ni particles attached to the tips of CNTs, indicating a tip growth mechanism.

It is interesting to note that only high structural quality of CNTs is not what is always desired for every application, instead there are some applications where defective CNTs perform better, such as battery anodes to store $\mathrm{Li}$ ions, $\mathrm{H}_{2}$ storage and $\mathrm{CO}_{2}$ storage, as the defects not only provide more entry points but also increase the surface area of CNTs and reduce the diffusion length $[160,161]$. CNT growth at low temperatures is a natural route to obtain structure defects. Raymundo et al. grew CNTs at $450-600{ }^{\circ} \mathrm{C}$ by Co based catalytic decomposition of $\mathrm{C}_{2} \mathrm{H}_{2}$, which produced low structural quality of CNTs grown at $450{ }^{\circ} \mathrm{C}$ and higher at $600{ }^{\circ} \mathrm{C}[160]$. They found that the chemical activation with $\mathrm{NaOH}$ is only effective with disordered CNTs and concluded that structural quality is an important parameter in the activation of CNTs with alkali reactants.

In short, various approaches adopted for the low temperature CVD growth of CNTs mainly include: (i) selecting an easy to crack carbon feedstock such as $\mathrm{C}_{2} \mathrm{H}_{2}$, cyclopentene oxide, waste gas mixture of Fischer-Tropsch process comprising unsaturated hydrocarbons; (ii) lowering the decomposition temperature of carbon feedstock by oxidative dehydrogenated reaction; (iii) using plasma and its various forms; (iv) using an engineering solution such as multi-zone CVD temperature where decomposition of carbon feedstock is conducted in high temperature zone whereas the growth occurs in low temperature zone; (v) catalyst conditioning to form active nanoparticles at low temperatures, e.g. using a bi- or tri-layered catalyst system such as Ni-Co, Ni-Co-Fe, co-catalyst systems such as using $\mathrm{Mo}, \mathrm{Cu}, \mathrm{Ti}$ and $\mathrm{Al}$ with a catalyst and solution processed catalyst. Despite encouraging results seen in some of the reports, structural quality and growth rate of CNTs are directly affected when the growth is performed at low temperatures. The CNT growth using the PTCVD system (following section) offers an engineering solution to conduct the growth at high temperatures to achieve high quality CNTs while the substrate remains at low temperature. 


\subsection{CNT growth using photo-thermal CVD}

In view of the above reports, it is evident that the structural quality and growth rate of CNTs are adversely affected when the growth is conducted at low temperatures. Arc-discharge and laser ablation produced CNTs show highest structural quality whereas CVD grown CNTs exhibit structural defects which are increased with decreasing growth temperature $[78,93,131]$. Many applications of CNTs such as flexible electronic devices and interconnects require high quality CNTs grown at temperatures below $450{ }^{\circ} \mathrm{C}$ which are back-end of line (BEOL) compatible, as higher temperatures can damage the substrate, may cause unwanted reactions or internal dislocations of precisely added impurities, which subsequently can degrade device functionality. The NEC group of the University of Surrey along with Surrey Nanosystems Ltd. have built a unique state-of-the-art system called PTCVD (Fig. 12a) where the substrate temperature can be controlled below $400{ }^{\circ} \mathrm{C}$ and CNT growth can be conducted at higher temperatures to achieve better quality and faster growth $[58,79]$.

In PTCVD, a water-cooled substrate holder is utilized to keep the bulk temperature of the substrate low, while an array of 8 lamps of $1 \mathrm{~kW}$ each in the optical head delivers energy directly onto the catalyst from the top [58-61]. In this arrangement a temperature gradient is created between the bulk temperature of a substrate and the catalyst layer at the top, as shown in Fig. 12b where the bulk temperature of a $\mathrm{Si}$ wafer is recorded by a pyrometer at its backside and the top surface temperature is recorded by a thermocouple [162]. The temperature in the PTCVD system is mainly controlled by the electrical power supplied to the lamps, however choice of a carrier gas and chamber pressure also affect the temperature as shown in Fig. 12c, where it can be observed that $\mathrm{H}_{2}$ is more efficient in removing the excess heat out of the chamber than Ar, and higher chamber pressures are more effective in keeping the temperature low [58]. Coating of a suitable material as a thermal barrier layer on a substrate also helps to keep the substrate temperature low by reflecting the optical energy back to the catalyst as shown in Fig. 12d, where various thicknesses of $\mathrm{Ti}$ as a thermal barrier layer coated on a Si substrate show their relative effectiveness [58].

As there is a temperature gradient between the top surface and the bulk of the substrate, it is difficult to tally the pyrometer reading with the exact point in the body of the substrate. However, as the pyrometer reads the recordable radiations emitted from the hottest point of the substrate and also taking the role of gas pressure and thermal barrier layer into account, it is reasonable to assume that the temperature recorded by the pyrometer is close to the top surface of the sample and thus bulk of the substrate remains unaffected by the high temperatures. We couldn't find a direct way of validating this assumption, however we've demonstrated CNT growth using the PTCVD system on some of the temperature sensitive substrates such as a microscopic glass slides (fisherbrand 1238-3118, thickness: 1.0-1.2 mm), on an ITO coated glass (soda lime float, thickness: $0.7 \mathrm{~mm}$, Product: LTG001, company: Luminescence Technology Corp) and on a polyimide (PI-5878G, HD MicroSystemsTM) coated Si substrate without damaging these materials (Fig. 13a, b). The SEM images of the CNTs grown on a glass slide and on an ITO coated glass are shown in Fig. 13a, b, where a good growth of vertically aligned CNTs with length greater than two microns can be observed without any apparent damage to the substrates [162]. The same samples were heavily damaged when the growth was conducted in a conventional CVD system (5002 SNS Nanocat) at $600{ }^{\circ} \mathrm{C}$ (Fig. 13c, d) [162]. Thus, the successful growth of CNTs on ITO and glass slide highlights the potential of the PTCVD system for CNT growth on temperature sensitive substrates.

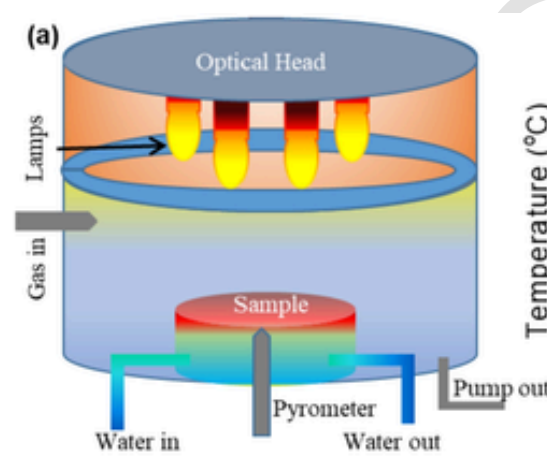

(c)

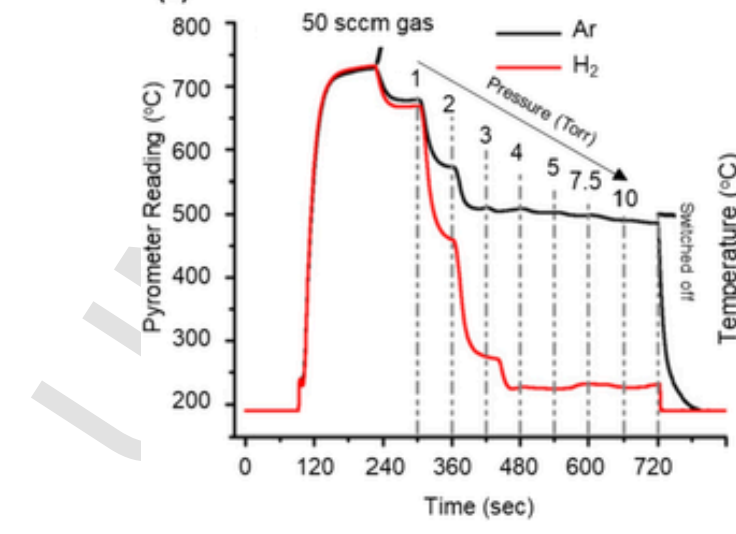

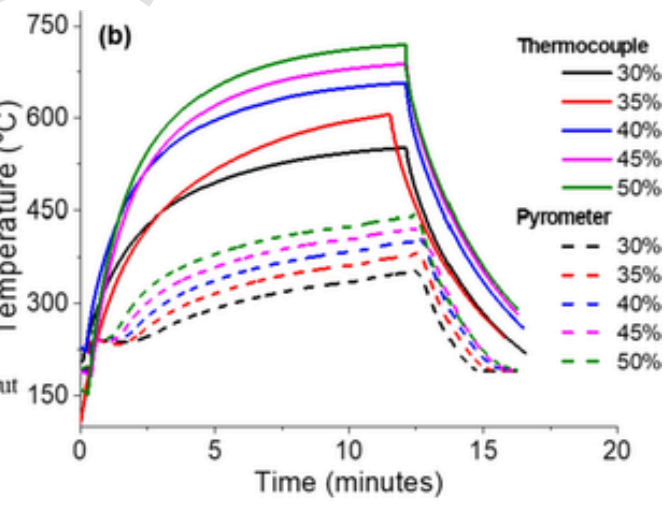

(d)

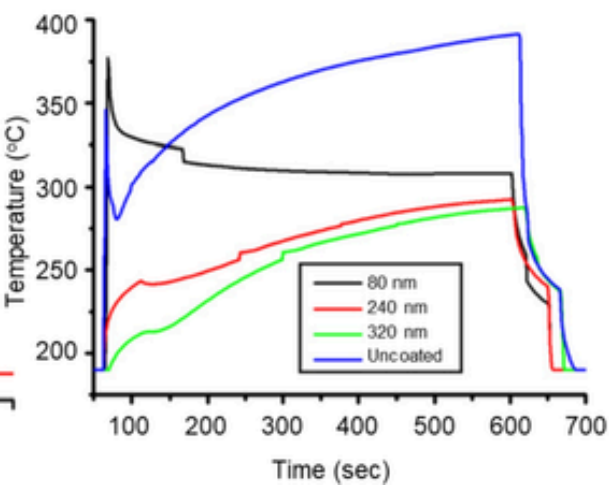

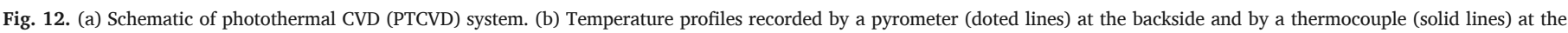

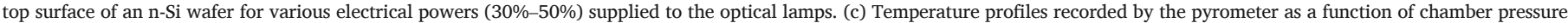

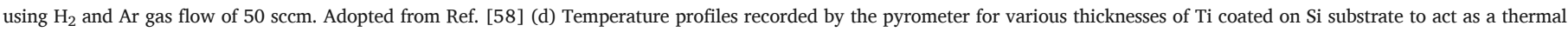
barrier layer. ((c, d) are reprinted from Ref. [58], copyright 2011, with permission from Elsevier). (A colour version of this figure can be viewed online.) 

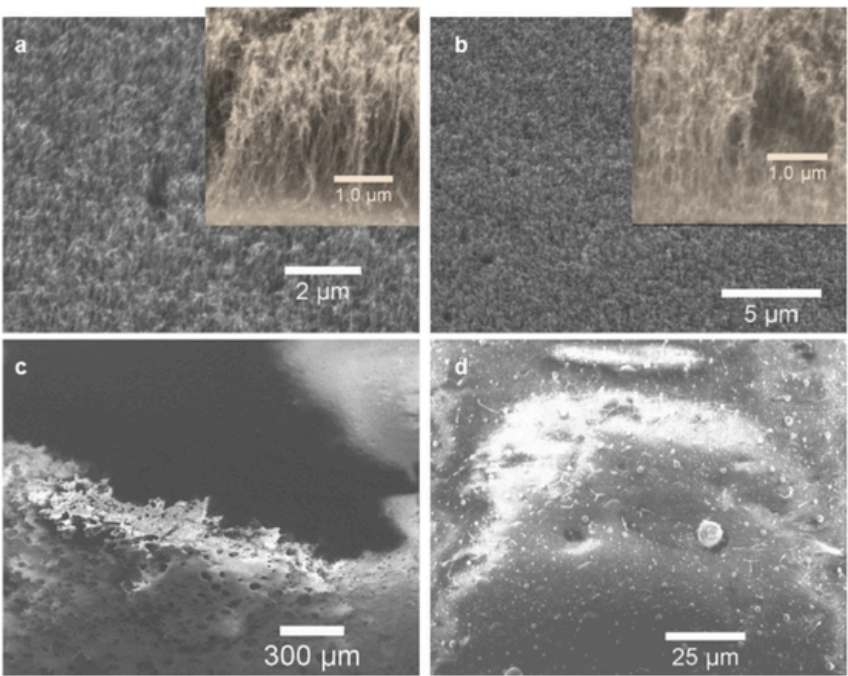

Fig. 13. (a, b) SEM images of the CNTs grown on a microscopic glass slide and on ITO coated glass sample using PTCVD system at a substrate bulk temperature $375{ }^{\circ} \mathrm{C}$. Insets show SEM images of the cross-section of the samples where good vertically aligned CNTs with lengths in excess of $2 \mu \mathrm{m}$ can be observed. (c, d) SEM images of the glass slide and ITO samples after a CNT growth process carried out in a conventional bottom-heating CVD system at $600{ }^{\circ} \mathrm{C}$, where the samples can be seen damaged heavily. Adopted from Ref. [162]
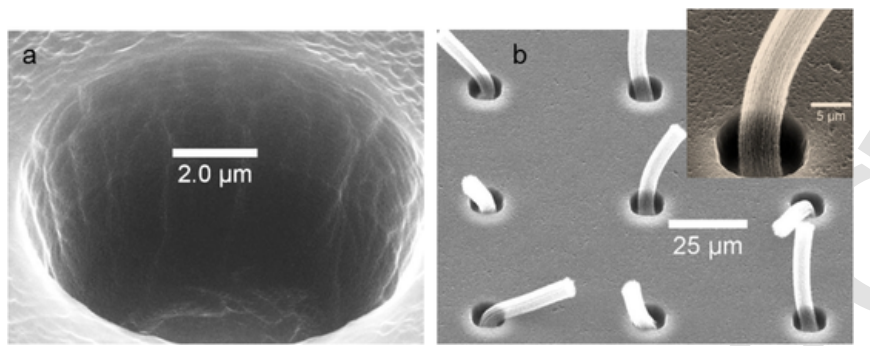

Fig. 14. (a) SEM image of a hole of $14 \mu \mathrm{m}$ depth etched in the polyimide film. (b) SEM image of the CNT growth in deep vias etched in the polyimide film; inset shows magnified image. Adopted from Ref. [162].
We have demonstrated the low temperature growth of CNTs in deep via holes (up to $20 \mu \mathrm{m}$ depth) fabricated on a polyimide (PI-5878G) coated Si substrate. The demonstration of CNT growth in deep holes is particularly relevant for interconnect via as well as through $\mathrm{Si}$ via applications. A layer stack of $\mathrm{TiN} / \mathrm{Al} / \mathrm{Fe}$ was sputtered on Si substrate followed by spin coating and curing of the polyimide film. After lithographic patterning, via holes were etched in the polyimide layer using oxygen plasma, as shown in Fig. 14a. Growth of CNTs was conducted for $10 \mathrm{~min}$ in the PTCVD system at a substrate bulk temperature of $400{ }^{\circ} \mathrm{C}$ using $\mathrm{H}_{2}(100 \mathrm{sccm})$ and $\mathrm{C}_{2} \mathrm{H}_{2}(10 \mathrm{sccm})$ at 2 Torr chamber pressure. Growth of high quality CNTs with length $\sim 50 \mu \mathrm{m}$ in all holes without any apparent damage to the polyimide layer was achieved, as can be seen in Fig. 14b.

Over the years, a remarkable progress has been made in the growth of CNTs using the PTCVD system $[60,77,79,162]$. We have demonstrated CNT growth on a range of substrate materials including Si, Steel, $\mathrm{Cu}$ foil, glass slides and polyimide coated $\mathrm{Si}$. We described how efficient coupling of optical energy at the CNT growth front can produce high-quality CNTs with high growth rates, in excess of $3 \mu \mathrm{m} / \mathrm{min}$, and at low substrate temperatures [60]. Vertically aligned CNT growth occurred on photolithographically patterned $\mathrm{Ti} / \mathrm{Cu} / \mathrm{TiN} / \mathrm{Al} / \mathrm{Fe}(20 / 150 /$ $50 / 10 / 3 \mathrm{~nm}$ ) layered structure sputtered on $\mathrm{n}$-Si substrates, using 10 sccm of $\mathrm{C}_{2} \mathrm{H}_{2}$ and $100 \mathrm{sccm} \mathrm{H}_{2}$ at 2 Torr pressure for various time durations at a substrate bulk temperature below $415{ }^{\circ} \mathrm{C}$ (Fig. 15a-d). The CNT growth was observed for the growth duration as low as $15 \mathrm{~s}$ (Fig. 15a) and the length of the CNTs increased linearly with increasing the growth duration as shown in Fig. 15e. Maximum height of the CNTs achieved in this study was around $63 \mu \mathrm{m}$ for a growth duration of $20 \mathrm{~min}$ [60].

The Raman spectra (using $514 \mathrm{~nm}$ wavelength) of all the CNT samples show well-defined first order and second order features, as shown in Fig. 16a which is the Raman spectrum of CNTs grown for $20 \mathrm{~min}$. Low $\mathrm{I}_{\mathrm{D}} / \mathrm{I}_{\mathrm{G}}$ values $(0.67-0.44)$ and fully developed $2 \mathrm{D}$ peaks in the Raman spectra were observed which indicate high quality of the CNTs. We noted a step decrease in the $\mathrm{I}_{\mathrm{D}} / \mathrm{I}_{\mathrm{G}}$ values from 0.67 to lower values (0.51-0.44) as the CNT growth duration was increased beyond $1 \mathrm{~min}$. The analysis of the data in Fig. 16b reveals that the values of $\mathrm{I}_{\mathrm{D}} / \mathrm{I}_{\mathrm{G}}$ for CNTs grown for short times (up to $1 \mathrm{~min}$ ) are similar to each other $(0.62-0.67)$ but then there is a step decrease to 0.51 when the
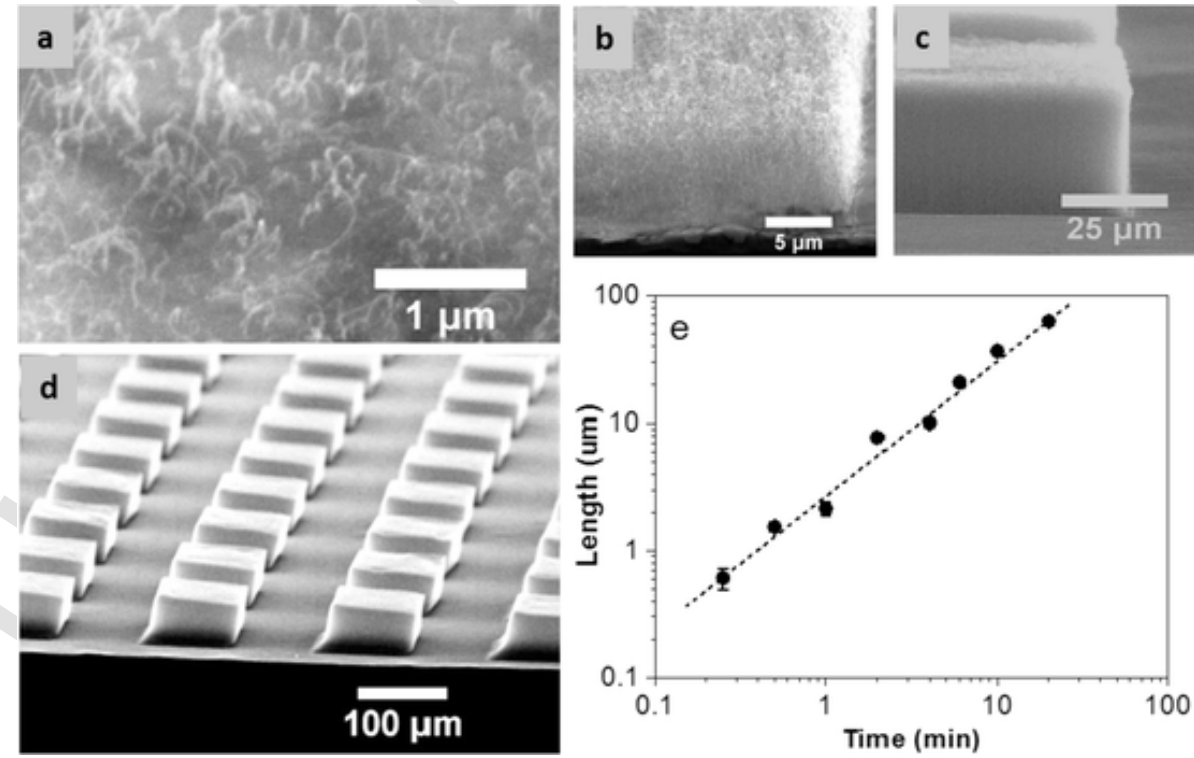

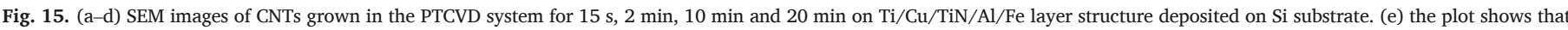

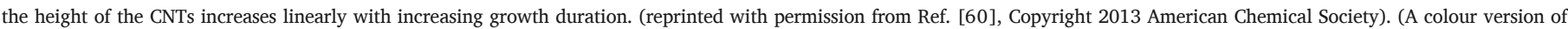
this figure can be viewed online.) 

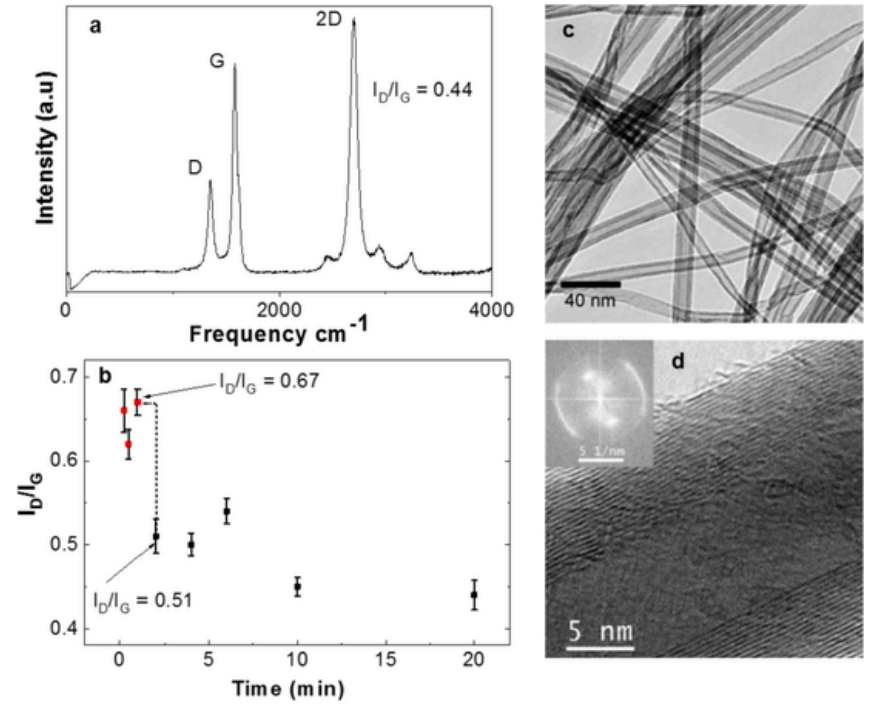

Fig. 16. (a) Raman spectrum (514 nm laser wavelength) of CNTs grown for 20 min showing distinct features, high G-peak and low D-peak which indicates high structural quality. (b) Variation of the $\mathrm{I}_{\mathrm{D}} / \mathrm{I}_{\mathrm{G}}$ values are plotted against the CNT growth durations. (c) TEM image shows high-quality CNTs, maintaining long-range orders in them. (d) HRTEM image and FFT in the inset show that the walls of CNTs are well-graphitized with long-range ordering. (reprinted with permission from Ref. [60], Copyright 2013 American Chemical Society). (A colour version of this figure can be viewed online.)

growth time was increased to $2 \mathrm{~min}$. We associate this step decrease with the absorption properties of the growing CNT forest. As the CNT forest grows taller for longer growth durations, it itself absorbs optical energy, which is coupled directly at the growth front and results in high structural quality of the CNTs which is reflected by the step decrease in the $\mathrm{I}_{\mathrm{D}} / \mathrm{I}_{\mathrm{G}}$ values [60].

TEM images of the CNTs (Fig. 16c, d) also show high structural quality of the CNTs with very clean straight walls and long-range hollow structural order in them. The mean diameter of the CNTs is estimated to be $14 \pm 4 \mathrm{~nm}$ with an average of $9 \pm 4$ shells. From these results, we inferred that the high quality of the CNTs is a result of the efficient energy delivery and coupling at the top surface of the samples, contrary to the conventional hot-wall CVD methods where the energy transfer to the catalyst is through the substrate, damaging the substrate first and reducing the energy at the growth front [60].

We also studied the growth initiation as a function of catalyst heat-treatment (HT) time and temperature which led us to propose a PTCVD rapid-growth-process (RGP) where the process time (catalyst preheating and growth time) to grow CNTs of length in excess of a micrometer is less than $4 \mathrm{~min}$ [60]. We performed HT for 5-7 min and found that the growth initiates immediately when the HT time is greater than $7 \mathrm{~min}$ and the substrate top surface temperature higher than $650{ }^{\circ} \mathrm{C}$ (Fig. 17a-c). This made us curious to check the CNT growth for the temperature above $650{ }^{\circ} \mathrm{C}$ and $\mathrm{HT}$ time lower than $7 \mathrm{~min}$.

As the temperature in the PTCVD system depends critically on the flow of the gases and pressure inside the chamber, we utilized this attribute of the system to confirm our assumption. We turned the lamps on at $40 \%$ power under vacuum $\left(1.6 \times 10^{-5}\right.$ Torr $)$ with no gas flowing through the chamber. This allowed the surface temperature of the sample to increase rapidly reaching at $659^{\circ} \mathrm{C}$ in just $2 \mathrm{~min}$ and $35 \mathrm{~s}$ (Fig. 17d). After this, $\mathrm{H}_{2}$ was introduced, the pressure was controlled to 2 Torr and $\mathrm{C}_{2} \mathrm{H}_{2}$ was introduced for $1 \mathrm{~min}$. A good growth of CNTs with length in excess of a micrometer occurred, as can be seen in the SEM image shown in Fig. 17e. We call it rapid growth process (RGP) as to our knowledge, the total process time (temperature rising + HT and growth time) is the shortest (less than $4 \mathrm{~min}$ ) ever reported for the CVD growth of CNTs with length $>1 \mu \mathrm{m}$. Beside the PTCVD ability of increasing the temperature rapidly, the chamber cooling down is
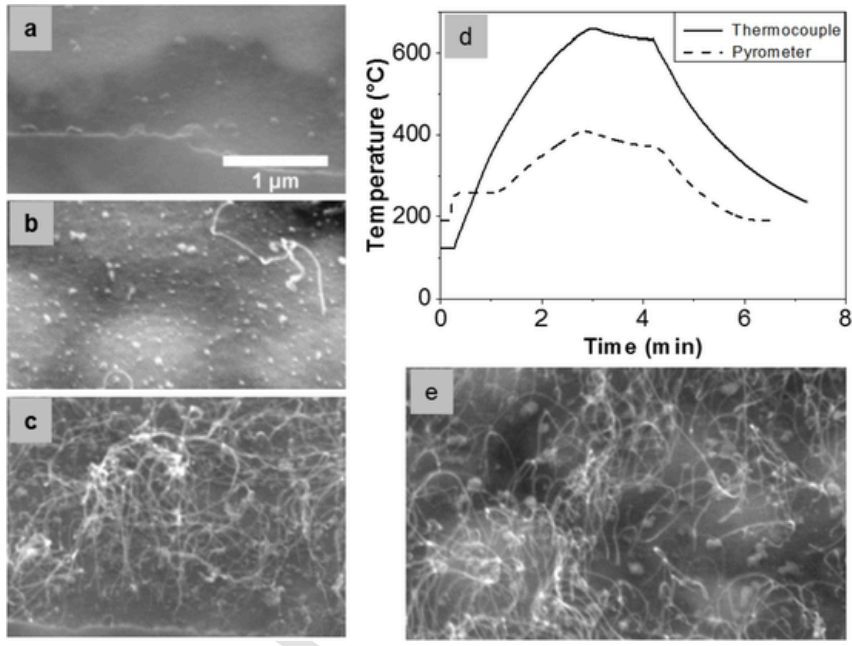

Fig. 17. (a-c) SEM images for 1 min growth after 5, 6 and 7 min HT show: (a) no CNT growth for $5 \mathrm{~min} \mathrm{HT}$; (b) some tubes for $6 \mathrm{~min} \mathrm{HT}$ and (c) good growth of CNTs for $7 \mathrm{~min}$ HT. (d) Temperature profiles of the CNT rapid growth process where the total processes time remains below 4 min to grow CNTs of lengths greater than a micrometer. (e) SEM image of the CNTs grown using the rapid growth process where the growth process time is less than $4 \mathrm{~min}$. Scale bar in all SEM images is same. (reprinted with permission from Ref. [60], Copyright 2013 American Chemical Society). (A colour version of this figure can be viewed online.)

also incredibly fast, compared with conventional hot wall CVD systems (Fig. 17d). The advantages of the RGP are reduced process time, reduced time that the substrate spends at elevated temperatures thereby reducing thermal strain, reduced power and gas consumption; thus, reducing the cost of the CNT growth.

An important aspect of the PTCVD growth is the freedom to engineer the substrate parameters to reflect the optical energy back to the catalyst, using the thin film constructive interference phenomenon [79]. For this, we coated various thicknesses $(50-200 \mathrm{~nm}$ ) of a TiN film on Si substrate followed by the deposition of $10 \mathrm{~nm} \mathrm{Al}$ and $3 \mathrm{~nm}$ Fe catalyst, and conducted the growth in the substrate bulk temperature range of $350-440{ }^{\circ} \mathrm{C}$ [79]. SEM images of the CNTs grown at substrate bulk temperature of $400{ }^{\circ} \mathrm{C}$ are shown in Fig. 18a-d, where different CNT heights $(7-28 \mu \mathrm{m})$ can be observed for various thicknesses of the TiN film, despite the same growth conditions.

TEM analysis showed that the CNTs grown with $50 \mathrm{~nm}$ TiN and $100 \mathrm{~nm}$ TiN are of diameter $9 \pm 3 \mathrm{~nm}$ and $5 \pm 1 \mathrm{~nm}$, respectively, and that the later are mainly double-wall with a considerable fraction of SWCNTs. Raman spectra also exhibit dependence on the TiN thickness, as can be observed in Fig. 18e, $\mathrm{f}$ which shows clearly distinctive Raman features for the CNTs grown with $50 \mathrm{~nm}$ TiN and $100 \mathrm{~nm}$ TiN under the same CVD conditions. This implies that the energy reflected back to the catalyst by the TiN-Si interface can be controlled effectively by adjusting the thickness of the TiN layer, which enables us to engineer the condition for maximum coupling of energy at the CNT growth front, resulting in the growth of very high quality CNTs $\left(\mathrm{I}_{\mathrm{D}} / \mathrm{I}_{\mathrm{G}}: 0.13\right)$ and a high growth rate $(\sim 6 \mu \mathrm{m} / \mathrm{min})$, despite the growth performed at a low substrate temperature $\left(420^{\circ} \mathrm{C}\right)$. In comparison with literature, commonly reported values of $\mathrm{I}_{\mathrm{D}} / \mathrm{I}_{\mathrm{G}}$ (for $514 \mathrm{~nm}$ laser wavelength) are from 0.9 to 0.4 in the CNT growth temperature range of $600-1100{ }^{\circ} \mathrm{C}$ $[78,132,163,164]$. The $\mathrm{I}_{\mathrm{D}} / \mathrm{I}_{\mathrm{G}}$ values are much higher $(>2)$ for the CNTs grown in the low temperature range $\left(400-550{ }^{\circ} \mathrm{C}\right)[132,165]$. Similarly, the growth rate of CNTs is very low $(0.05-1.3 \mu \mathrm{m} / \mathrm{min})$ when the growth is performed on metallic layers using conventional CVD techniques at low temperatures $[103,133]$.

AFM analysis revealed that the thickness of the TiN film also affects the catalyst particle size and distribution, which can be conditioned to control the diameter of the CNTs and to grow conductivity type selected carbon nanotubes. Fig. 19(a-d) shows the AFM images of the 

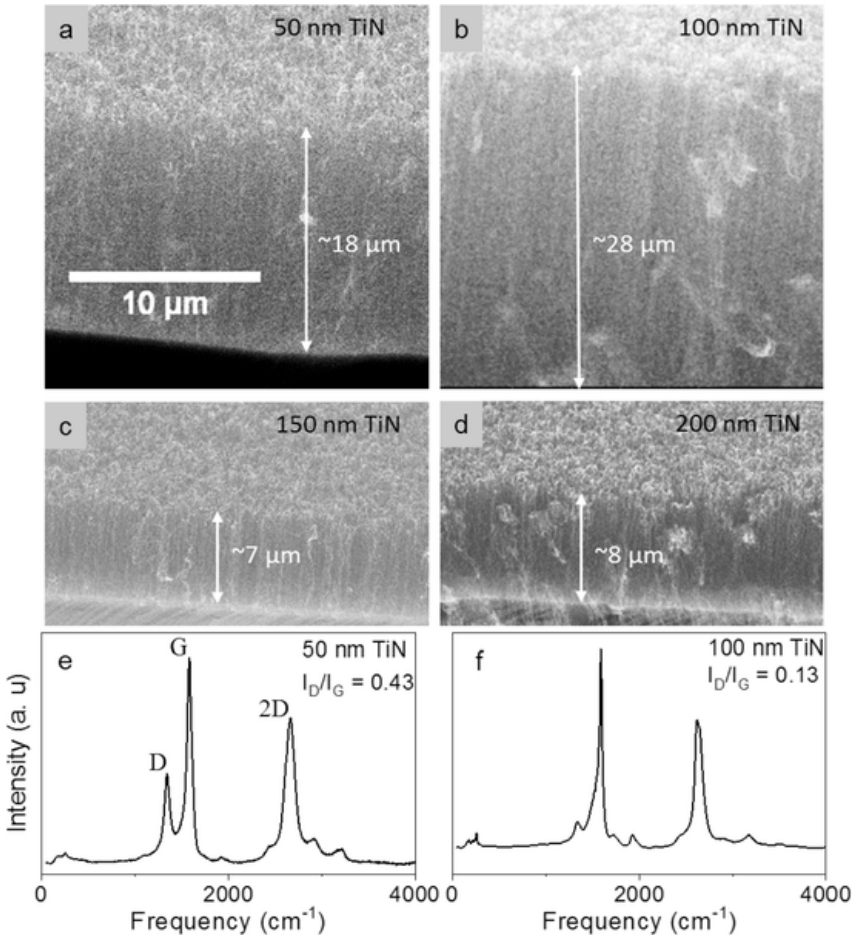

Fig. 18. (a-dd) SEM images show CNT height $(7-28 \mu \mathrm{m})$ dependence on the thickness of the TiN film (scale bar on all the SEM images are same). (e, f) Raman features of the CNTs grown with $50 \mathrm{~nm}$ TiN and that with $100 \mathrm{~nm}$ TiN are clearly distinguishable from each other (reprinted with permission from Ref. [79], (C) 2015 WILEY-VCH Verlag GmbH \& Co. KGaA, Weinheim).

Fe catalyst particles for 50 and $100 \mathrm{~nm}$ TiN, and their respective size distribution. The sample with $100 \mathrm{~nm}$ TiN shows narrow distribution of the catalyst particles with mean diameter of $5 \pm 3$, as compared with that of $50 \mathrm{~nm}$ TiN where the mean diameter is $10 \pm 6$. The corresponding CNT diameter found by TEM analysis matches well with the diameter of the catalyst nanoparticles. Fig. 19b shows the Raman radial breathing mode (RBM) analysis of the CNTs grown using 100 $\mathrm{nm}$ TiN at various catalyst conditioning temperatures. The analysis of RBM region can be used to estimate the production yield of semiconducting and metallic SWCNTs; for a laser energy of $2.41 \mathrm{eV}(514 \mathrm{~nm}$ wavelength), $150-210 \mathrm{~cm}^{-1}$ spectral range corresponds to semiconducting SWCNTs whereas $210-280 \mathrm{~cm}^{-1}$ corresponds to metallic SWCNTs $[77,166]$. In view of this, Fig. 19e shows that there is a preferential growth of metallic CNTs for the catalyst conditioning at $400{ }^{\circ} \mathrm{C}$ and $420{ }^{\circ} \mathrm{C}$, whereas the catalyst conditioning at $440{ }^{\circ} \mathrm{C}$ results in a high fraction of semiconducting CNTs.

Selective growth of metallic and semiconducting CNTs is also demonstrated in one of our other studies [77]. In this report, a detailed study of PTCVD growth of CNTs as a function of temperature, gas ratio and gas flow is conducted to determine the growth window for quality, growth rate and conduction type of the CNTs. The CNT growth on $\mathrm{Ti} / \mathrm{Al} / \mathrm{Fe}(30 / 30 / 5 \mathrm{~nm})$ layers deposited on $\mathrm{Si}$ substrate was conducted in the substrate temperature range of $320-515{ }^{\circ} \mathrm{C}$ which corresponds to $570-880{ }^{\circ} \mathrm{C}$ of the catalyst temperature at the top surface of the sample. The samples were pre-annealed in $\mathrm{H}_{2}$ environment for 5 min at 2 Torr pressure and the growth was conducted using a mixture of $\mathrm{C}_{2} \mathrm{H}_{2} / \mathrm{H}_{2}$ for $10 \mathrm{~min}$. The $\mathrm{C}_{2} \mathrm{H}_{2} / \mathrm{H}_{2}$ ratio $\left(\mathrm{Q}_{\mathrm{A} / \mathrm{H}}\right)$ was varied from $2 \%$ to $20 \%$ to see its effect on the CNT growth. A set of experiments was also performed by doubling the gas flow rate from 100 to $200 \mathrm{sccm}$, while keeping the gas ratios and remaining parameters unchanged. The CNT quality increases mainly with increasing temperature but also with decreasing $\mathrm{C}_{2} \mathrm{H}_{2}$ ratio. The growth rate (Fig. 20a) increases with increasing $\mathrm{C}_{2} \mathrm{H}_{2}$ in the gas mixture and a maximum growth rate of $442 \mathrm{~nm} / \mathrm{s}$ achieved for $18 \%$ gas ratio at high flow rate $(200 \mathrm{sccm})$ and a substrate temperature of $447{ }^{\circ} \mathrm{C}$ (Fig. 20a), which produced vertically aligned CNTs of length greater than $300 \mu \mathrm{m}$ (Fig. 20b). Growth of SWCTs was also observed at a lowest substrate temperature of $320^{\circ} \mathrm{C}$. The quantitative Raman analysis of RBM region for selective growth of metallic and semiconducting tubes (m-CNTs and s-CNTs) is presented using laser energies of 2.41 and $1.58 \mathrm{eV}$, where $2.41 \mathrm{eV}$ is used to probe both s-CNT and m-CNTs and $1.58 \mathrm{eV}$ only probes the s-CNT (Fig. 20c). The growth window for $\mathrm{m}$-CNT is found to be wider than for s-CNTs, and the smaller acetylene ratio $(<10 \%)$ favors the growth of s-CNTs but the higher ratio $(>10 \%)$ favors the growth of m-CNTs.
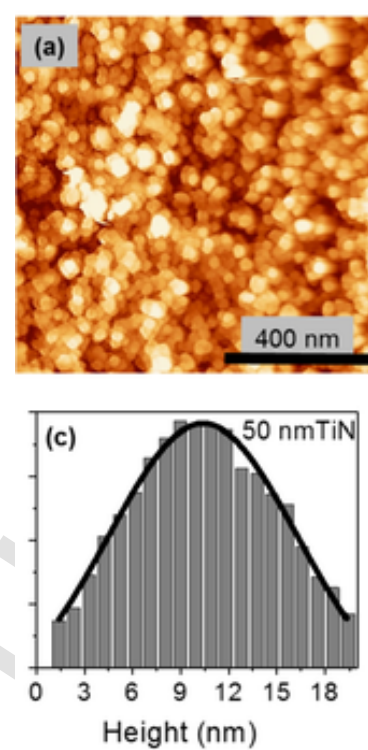
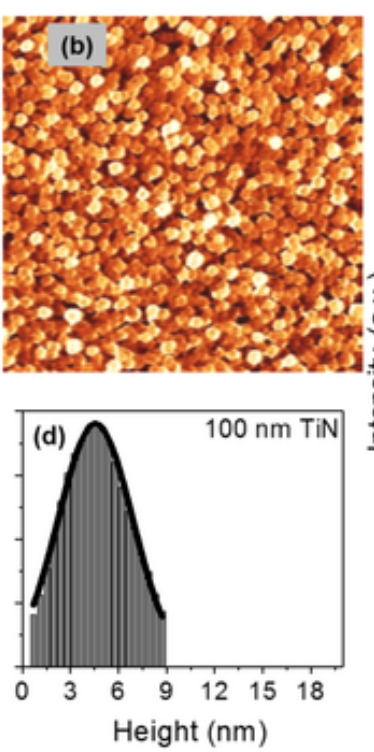

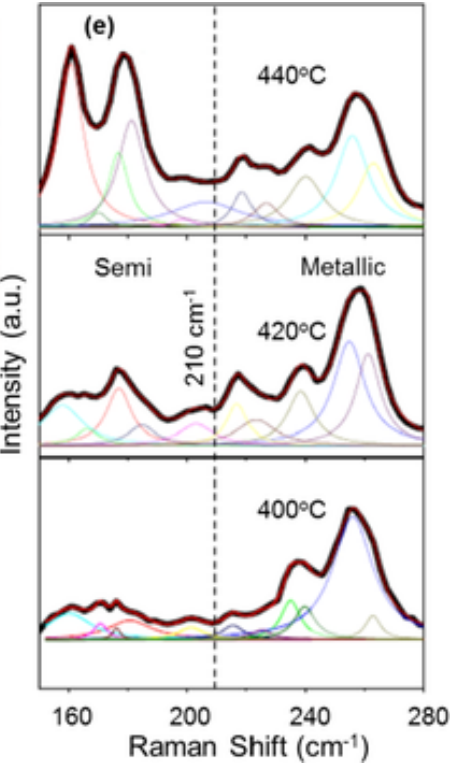

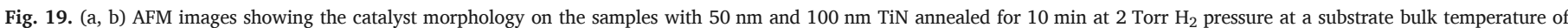

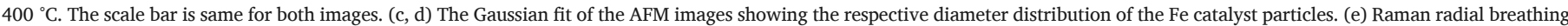

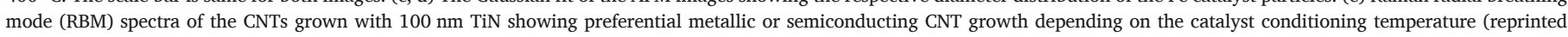
with permission from Ref. [79], (C) 2015 WILEY-VCH Verlag GmbH \& Co. KGaA, Weinheim). 

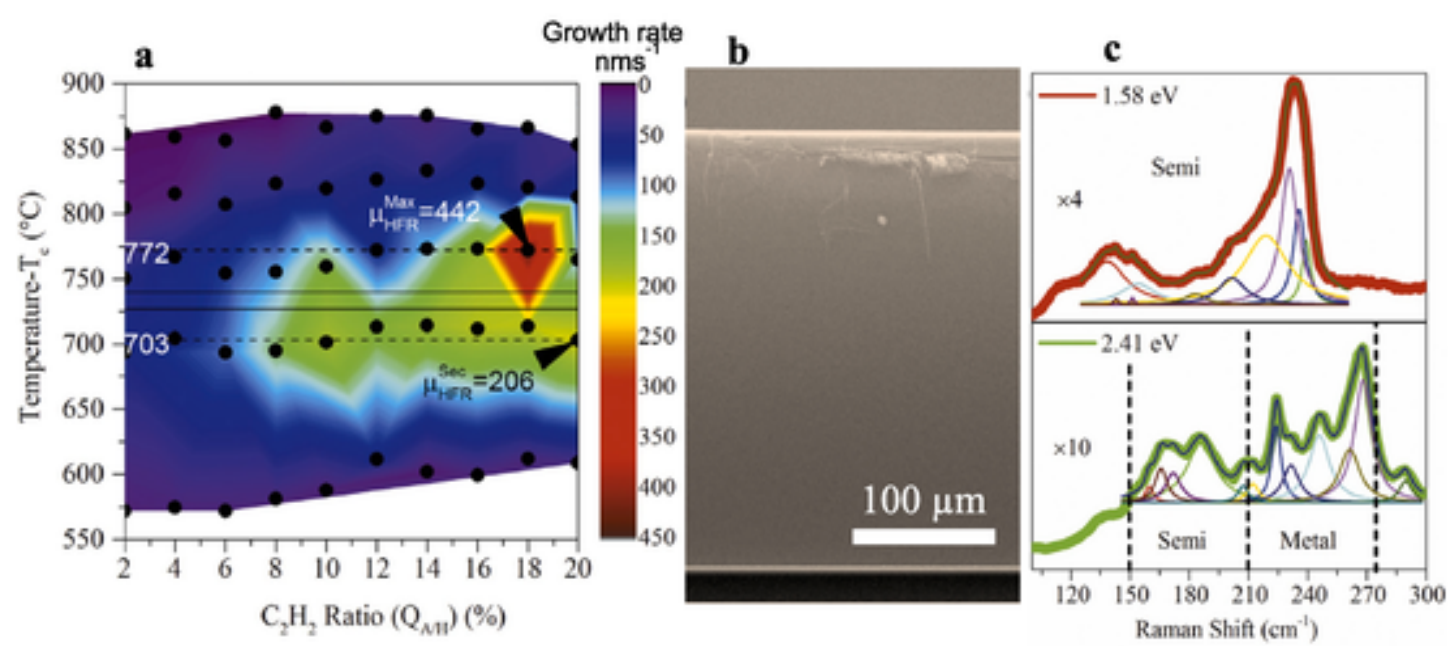

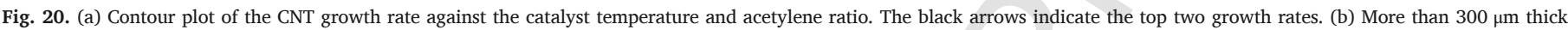

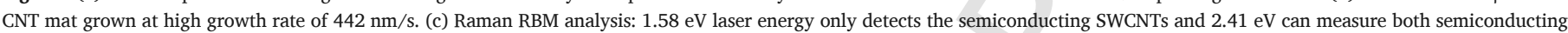

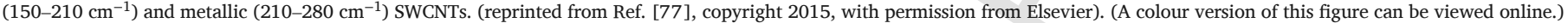

Recently, we introduced a novel 'protected catalyst method' for the low temperature growth of CNTs and graphene [56]. The method involves capping the catalyst with a layer of a suitable material, e.g. TiN, $\mathrm{Cr}$, Ta, which protects it from environmental contaminants such as oxidation and etchant attack, whilst maintaining carbon supply to the catalyst for the growth of CNTs or graphene. The protection of a $3.0 \mathrm{~nm} \mathrm{Fe}$ catalyst film in the $\mathrm{CF}_{4}$ based reactive-ion-etching process by a $7.0 \mathrm{~nm}$ TiN film is demonstrated. XPS analysis confirms that the Fe catalyst capped by the protective layer remains protected from oxidation even after a year, which offers a unique capability of prolonging the shelf-life of growth-ready samples and their portability around the world. The protected catalyst method also offers greater control to tailor various parameters of CNTs and graphene such as growth rate, diameter, conductivity and number of layers. A significant advantage of the protected catalyst method is that it improves the adhesion of the CNTs with the substrate which is vital for the reliability of CNT based interconnects and other electronic devises.

\section{Low temperature growth of SWCNTs}

Low temperature growth of SWCNTs is less common as compared with the MWCNTs. This may be because of high energy requirement for the formation and activation of relatively smaller diameter catalyst nanoparticles and high curvature of growing CNTs. Mora et al. reported the growth of SWCNTs at $560{ }^{\circ} \mathrm{C}$ on Fe-Mo catalyst supported on $\mathrm{Al}_{2} \mathrm{O}_{3}$ powder using endothermic decomposition of $\mathrm{CH}_{4}$, without the assistance of a plasma [113]. At the gas outlet, they monitored $\mathrm{H}_{2}$ concentration as a function of temperature with the help of a mass spectrometer, while passing $\mathrm{CH}_{4} / \mathrm{Ar}$ mixture over unreduced and reduced catalyst particles through the reaction chamber and found that highly active catalyst particles reduced at $900{ }^{\circ} \mathrm{C}$ can lower the $\mathrm{CH}_{4}$ decomposition temperature up to $150{ }^{\circ} \mathrm{C}$ as compared with less active nanoparticles reduced under standard conditions (shown in Fig. 21a). Despite, the actual growth conducted in this paper being at relatively lower temperatures $\left(560{ }^{\circ} \mathrm{C}\right)$, the high activation of catalyst particles at $900{ }^{\circ} \mathrm{C}$ make this method less useful for temperature sensitive substrates. The diameter distribution of SWCNTs is reported as $0.7-2.0 \mathrm{~nm}$ with high $\mathrm{I}_{\mathrm{D}}$ to $\mathrm{I}_{\mathrm{G}}$ ratio, as estimated by the Raman spectrum.

Maruyama et al. demonstrated growth of high purity SWCNTs at relatively lower temperatures using alcohol as carbon feedstock [82]. The high purity is attributed to the production of $\mathrm{OH}$ radicals by the decomposition of alcohol on the catalyst surface, which etched away the amorphous carbon. They placed powdered $\mathrm{Fe} / \mathrm{Co}$ (or $\mathrm{Ni} / \mathrm{Co}$ ) (a)
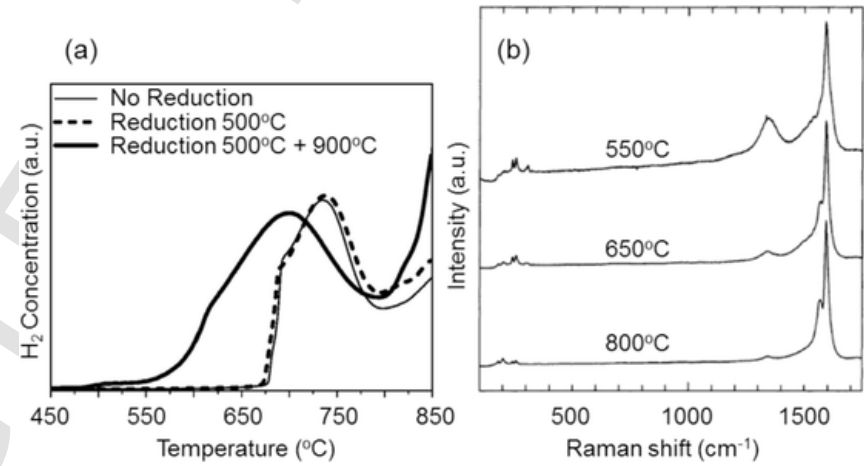

Fig. 21. (a) $\mathrm{H}_{2}$ concentration at the outlet resulted from the decomposition of $\mathrm{CH}_{4}$, indicating higher activity of the catalyst reduced at $900{ }^{\circ} \mathrm{C}$ at relatively lower temperatures. (reprinted with permission from Ref. [113], Copyright 2008 American Chemical Society). (b) Raman spectra of SWCNTs grown from methanol at various temperatures. (reprinted from Ref. [82], copyright 2002, with permission from Elsevier). (A colour version of this figure can be viewed online.)

catalyst supported with Zeolite $(\mathrm{MgO}$ for $\mathrm{Ni} / \mathrm{Co})$ in a tube furnace and conducted the growth in the temperature range of $550-900{ }^{\circ} \mathrm{C}$, using ethanol, methanol or 1-propanol as carbon feedstock. It was noted from the comparison of Raman spectra that optimum CNT growth temperature is about $50{ }^{\circ} \mathrm{C}$ less when methanol is used instead of ethanol. The CNTs grown at higher temperatures were of high quality with an average diameter of $1 \mathrm{~nm}$ and comprising of SWCNTs only, however at lower temperatures $\left(<600^{\circ} \mathrm{C}\right)$ increased intensity of the D peak and mixed growth of SWCNTs and MWCNTs was observed (Fig. 21b).

Bae et al. demonstrated SWCNT growth on $\mathrm{Si} / \mathrm{SiO}_{2}$ substrate at temperatures as low as $425^{\circ} \mathrm{C}$ using a home-built remote rf PECVD system where halogen lamps were used to provide the heat energy [167]. Various concentrations (0.01-0.3 M) of ferrocene mixed in AZ5214 photoresist was spin coated on the substrate and then heated in an $\mathrm{O}_{2}$ environment to burn out the resist. The growth was conducted in the temperature range of $350-500{ }^{\circ} \mathrm{C}$ using a plasma power of $15-440 \mathrm{~W}$ and a mixture of $\mathrm{CH}_{4} / \mathrm{Ar}$ at 0.4 Torr pressure. The growth of SWCNTs was observed at temperatures above $425{ }^{\circ} \mathrm{C}$ and the rf plasma power below $40 \mathrm{~W}$. A sharp decrease in the Raman $\mathrm{I}_{\mathrm{D}} / \mathrm{I}_{\mathrm{G}}$ ratio from 1.9 to 0.1 was observed when the rf plasma power was reduced from $90 \mathrm{~W}$ to $15 \mathrm{~W}$, which indicates that lower plasma powers produce better quality CNTs. The as-grown CNTs were tangled and sparse with their diameter ranging from 1.02 to $1.38 \mathrm{~nm}$. 
Cantoro et al. reported low temperature growth of SWCNTs using $\mathrm{Al} / \mathrm{Fe} / \mathrm{Al}$ catalyst layer structure evaporated on boron doped $\mathrm{Si}$ wafer covered with thermally grown $\mathrm{SiO}_{2}$ coating in a cold-wall CVD system where undiluted $\mathrm{C}_{2} \mathrm{H}_{2}$ as carbon feedstock was used [168]. A careful thermal treatment of the catalyst was performed in $\mathrm{NH}_{3}$ or $\mathrm{H}_{2}$ environment at various pressures in order to distinguish between the formation of rightly sized active catalyst particles and nucleation of SWCNTs. Vertically aligned growth of SWCNTs was observed at a minimum of $350{ }^{\circ} \mathrm{C}$. Maruyama et al. reported low yield growth of short (sub-micron) SWCNTs at $270{ }^{\circ} \mathrm{C}$ using e-beam evaporated Rh catalyst deposited on $\mathrm{Si}$ / $\mathrm{SiO}_{2} / \mathrm{Al}_{2} \mathrm{O}_{3}$ substrate by optimising ethanol supply and growth pressure [169]. Recently, they reported SWCNT growth below $300{ }^{\circ} \mathrm{C}$ on Co catalyst using the same structure $\left(\mathrm{Si} / \mathrm{SiO}_{2} / \mathrm{Al}_{2} \mathrm{O}_{3}\right)$ and technique [170].

Zhang et al. reported chirality-controlled growth of SWCNTs by keeping the Co catalyst in solid state using lower temperature $\left(650^{\circ} \mathrm{C}\right)$ [171]. Their method is based on the symmetry matching mechanism [172], where Co (100) face is used as template to grow horizontal arrays of near-armchair tubes $(10,9)$ with $75 \%$ selectivity and $(12,6)$ with $82 \%$ selectivity. They performed an additional annealing step of the catalyst in $\mathrm{H}_{2}$ environment at $450{ }^{\circ} \mathrm{C}$ to obtain rightly sized catalyst particles with better dispersion and activity. The catalyst was spin coated on quartz substrate using $\mathrm{Co}\left(\mathrm{NO}_{3}\right)_{2}$ ethanol solution. In order to achieve $(10,9)$ tubes requiring slower growth rate, they used minimum concentration of ethanol to tune the thermodynamic selectivity, whereas for $(12,6)$ tubes requiring higher growth rate, they used $\mathrm{CO}$ to provide higher concentration of carbon while etching away the excessive amorphous carbon by oxygen radicals to maintain the catalytic activity [171].

The main strategies utilized to achieve low temperature growth of CNTs using three major variants of CVD are summarized in Fig. 22. TCVD and PECVD grown CNTs at lower temperatures generally suffer from low structural quality and low growth rates as compared with those grown using PTCVD. Growth of high-quality carbon nanotubes at low temperatures has a great scope in present and future technologies, especially in the realization of the devices under the paradigm of
Internet of Things such as wearables, sensors, FETs, flexible battery electrodes, renewable energy harvesters, smart cloths, smart buildings, carbon electronics, etc. [28,173-176] As the CVD temperatures are still too high for the direct growth of CNTs on some of the temperature sensitive substrates such as plastic, so alternative routes are also being explored where CNTs are grown at higher temperatures and then transferred to the desired substrate by solution processing, spray coating, drop casting and spin coating $[28,177,178]$. However, we believe that direct growth of CNTs on the desired substrate would be a preferred choice when researchers are able to produce high quality CNTs at temperatures compatible with these substrates.

\section{Summary}

Remarkable progress has been made in the CVD growth of CNTs and understanding of its underlying growth mechanism. High growth rate of high quality CNTs with improved control of their various parameters such as length, diameter, chirality and metallicity is being realized. However, achieving the CNT growth at lower temperatures without compromising on their quality, growth rate and various other parameters of interest is still challenging. Various strategies have been adopted for the growth of CNTs at low temperatures which are mainly focused on achieving the carbon feedstock decomposition at low temperatures. One approach in the literature is to use a carbon feedstock with exothermal decomposition such as $\mathrm{C}_{2} \mathrm{H}_{4}, \mathrm{C}_{2} \mathrm{H}_{2}$, etc., the other involves the use of $\mathrm{CO}_{2}$ with a carbon feedstock for its decomposition through the oxidative dehydrogenation reaction. Various forms of PECVD are widely utilized to facilitate the low temperature decomposition and subsequent CNT growth. Apart from the decomposition of the carbon feedstock, formation of rightly sized catalyst nanoparticles and their activation at low temperatures is also a key parameter. A solid-state film of a catalyst generally requires higher temperatures for the formation and reduction of active nanoparticles than a solution-based coating of a catalyst material or pre-formed catalyst nanoparticles. Also, some catalyst materials such as Co are capable of growing CNTs at relatively lower temperature than others such as Fe. Multilayer or hybrid catalyst systems have also been reported effective in the formation of active nanoparticles at low temperatures. There are also

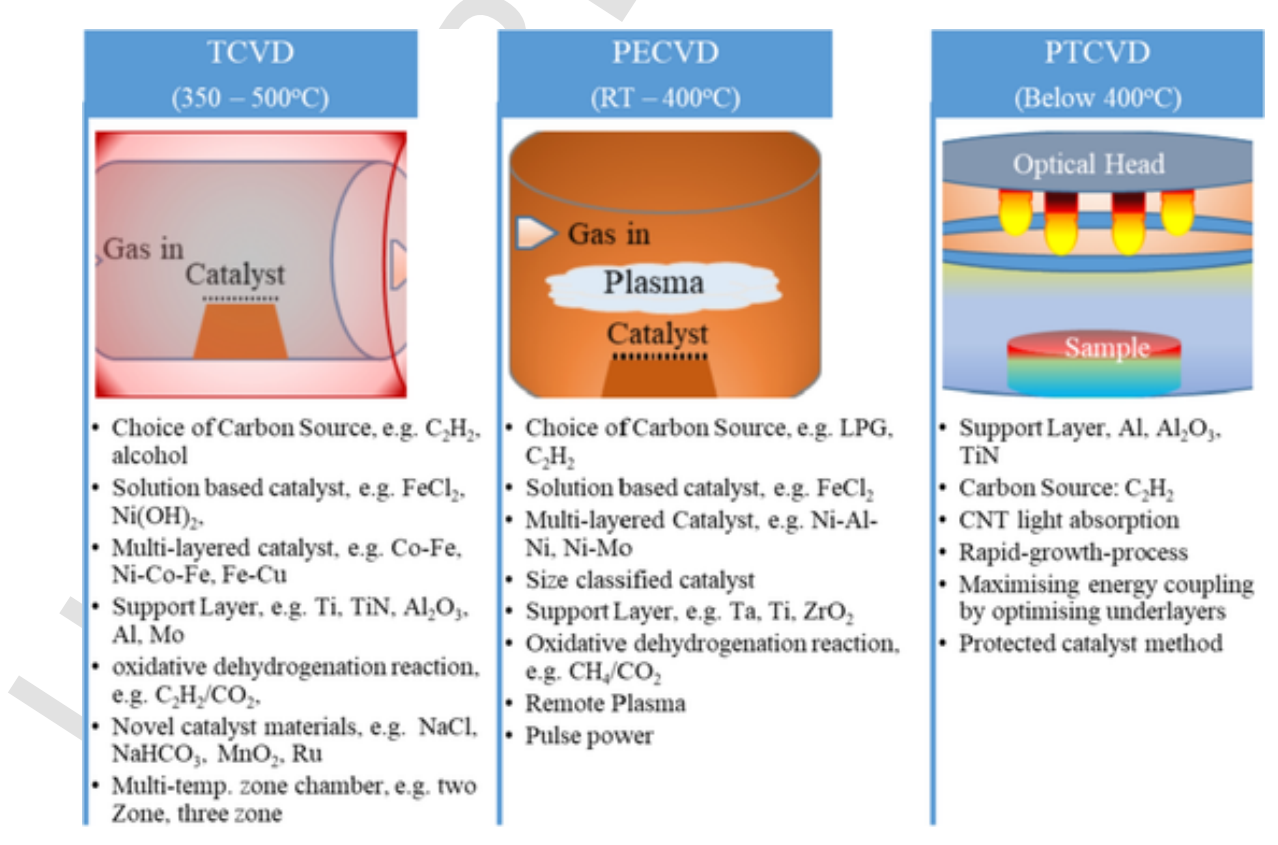

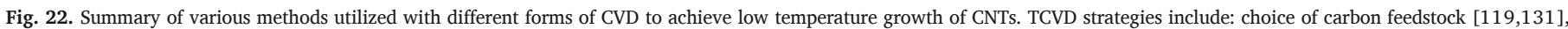

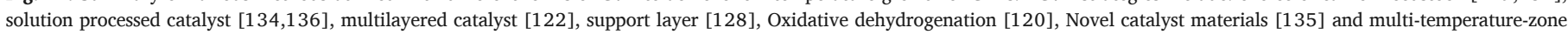

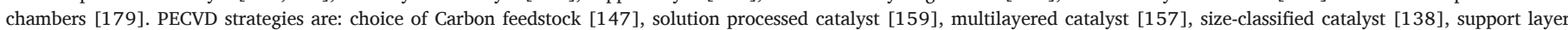

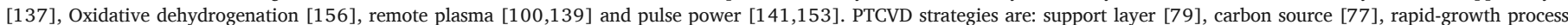
[60], maximizing energy coupling by optimising underlayers [79] and protected catalyst method [56]. 
some engineering solutions of achieving low temperature growth of CNTs which includes the use of a multi-zone CVD system and the PTCVD system. In the multi-zone CVD system, the decomposition of the carbon feedstock is performed in a higher temperature zone, whereas the CNT growth is conducted in a lower temperature zone. In PTCVD, optical energy is directly delivered to the catalyst while the bulk of the sample is kept at lower temperature using water-cooled sample holder. PTCVD can produce CNTs at low substrate temperatures without compromising their quality and growth rate.

\section{Declaration of competing interest}

The authors declare that they have no known competing financial interests or personal relationships that could have appeared to influence the work reported in this paper. Acknowledgements The authors acknowledge financial support from EPSRC (EP/L02263x/1 and EP/ R025304/1) in the conduct of this work.

\section{References}

[1] M.S. Dresselhaus, G. Dresselhaus, P. Avouris, Carbon Nanotubes: Synthesis, Structure, Properties, and Applications, Springer Book, 2001.

[2] N. Hamada, S. Sawada, A. Oshiyama, New one-dimensional conductors graphitic microtubules, Phys. Rev. Lett. 68 (10) (1992) 1579-1581.

[3] P. Avouris, Z. Chen, V. Perebeinos, Carbon-based electronics, Nat. Nanotechnol. 2 (10) (2007) 605-615.

[4] B.Q. Wei, R. Vajtai, P.M. Ajayan, Reliability and current carrying capacity of carbon nanotubes, Appl. Phys. Lett. 79 (8) (2001) 1172-1174.

[5] Q. Wen, R. Zhang, W. Qian, Y. Wang, P. Tan, J. Nie, F. Wei, Growing $20 \mathrm{~cm}$ Long DWNTs/TWNTs at a Rapid Growth Rate of 80-90 um/s, Chem. Mater. 22 (4) (2010) 1294-1296.

[6] B. Peng, M. Locascio, P. Zapol, S.Y. Li, S.L. Mielke, G.C. Schatz, H.D. Espinosa, Measurements of near-ultimate strength for multiwalled carbon nanotubes and irradiation-induced crosslinking improvements, Nat. Nanotechnol. 3 (10) (2008) 626-631.

[7] E. Pop, D. Mann, Q. Wang, K.E. Goodson, H.J. Dai, Thermal conductance of an individual single-wall carbon nanotube above room temperature, Nano Lett. 6 (1) (2006) 96-100.

[8] M.F.L. De Volder, S.H. Tawfick, R.H. Baughman, A.J. Hart, Carbon nanotubes: present and future commercial applications, Science 339 (6119) (2013) 535.

[9] S. Park, M. Vosguerichian, Z. Bao, A review of fabrication and applications of carbon nanotube film-based flexible electronics, Nanoscale 5 (5) (2013) 1727-1752.

[10] J.M. Schnorr, T.M. Swager, Emerging applications of carbon nanotubes, Chem. Mater. 23 (3) (2011) 646-657.

[11] O. Gohardani, M.C. Elola, C. Elizetxea, Potential and prospective implementation of carbon nanotubes on next generation aircraft and space vehicles: a review of current and expected applications in aerospace sciences, Prog. Aerosp. Sci. 70 (2014) 42-68.

[12] Y. Liu, Y. Zhang, C. Zhang, B. Huang, Y. Li, W. Lai, X. Wang, X. Liu, Low temperature preparation of highly fluorinated multiwalled carbon nanotubes activated by $\mathrm{Fe} 3 \mathrm{O} 4$ to enhance microwave absorbing property, Nanotechnology 29 (36) (2018) 365703.

[13] L. Liang, M. Xiao, J. Zhu, J. Ge, C. Liu, W. Xing, Low-temperature synthesis of nitrogen doped carbon nanotubes as promising catalyst support for methanol oxidation, J. Energy Chem. 28 (2019) 118-122.

[14] S. Pan, H. Lin, J. Deng, P. Chen, X. Chen, Z. Yang, H. Peng, Novel wearable energy devices based on aligned carbon nanotube fiber textiles, Adv. Energy Mater. 5 (4) (2015) 1401438.

[15] C.H. Yang, C.C. Su, K.P. Hsieh, Y.R. Li, K.Y. Yeh, S.H. Chang, Vertically Aligned Carbon Nanotubes Forest Based Flexible Strain Sensor for Internet of Things Applications, 2017 19th International Conference on Solid-State Sensors, Actuators and Microsystems (TRANSDUCERS), 2017, pp. 1360-1363.

[16] T. Yamada, Y. Hayamizu, Y. Yamamoto, Y. Yomogida, A. Izadi-Najafabadi, D.N. Futaba, K. Hata, A stretchable carbon nanotube strain sensor for human-motion detection, Nat. Nanotechnol. 6 (2011) 296.

[17] F. Liu, R.M. Wagterveld, B. Gebben, M.J. Otto, P.M. Biesheuvel, H.V.M. Hamelers, Carbon nanotube yarns as strong flexible conductive capacitive electrodes, Colloid Interface Sci. Commun. 3 (2014) 9-12.

[18] S.H. Kim, C.S. Haines, N. Li, K.J. Kim, T.J. Mun, C. Choi, J. Di, Y.J. Oh, J.P. Oviedo, J. Bykova, S. Fang, N. Jiang, Z. Liu, R. Wang, P. Kumar, R. Qiao, S. Priya, K. Cho, M. Kim, M.S. Lucas, L.F. Drummy, B. Maruyama, D.Y. Lee, X. Lepró, E. Gao, D. Albarq, R. Ovalle-Robles, S.J. Kim, R.H. Baughman, Harvesting electrical energy from carbon nanotube yarn twist, Science 357 (6353) (2017) 773.

[19] T. Takahashi, Z. Yu, K. Chen, D. Kiriya, C. Wang, K. Takei, H. Shiraki, T. Chen, B. Ma, A. Javey, Carbon nanotube Active-matrix backplanes for mechanically flexible visible light and X-ray imagers, Nano Lett. 13 (11) (2013) 5425-5430.

[20] H.-Y. Chiu, P. Hung, H.W.C. Postma, M. Bockrath, Atomic-scale mass sensing using carbon nanotube resonators, Nano Lett. 8 (12) (2008) 4342-4346.

[21] Vantablackhttps://www.surreynanosystems.com/vantablack

[22] AZoNano, BMC Unveil Carbon Nanotube Bike to Take on Tour de France - New Product, 2005. https://www.azonano.com/article.aspx?ArticleID = 1298.
[23] N. Fleming Should we give up on the dream of space elevators?BBChttp:// www.bbc.com19 February 2015

[24] K. Jiang, Q. Li, S. Fan, Spinning continuous carbon nanotube yarns, Nature 419 (6909) (2002) 801-801.

[25] S. Luo, Y. Wang, G. Wang, K. Wang, Z. Wang, C. Zhang, B. Wang, Y. Luo, L. Li, T. Liu, CNT enabled Co-braided smart fabrics: a new route for non-invasive, highly sensitive \& large-area monitoring of composites,, Sci. Rep. 7 (2017) 44056.

[26] X. Luo, W. Weng, Y. Liang, Z. Hu, Y. Zhang, J. Yang, L. Yang, S. Yang, M. Zhu, H.-M. Cheng, Multifunctional fabrics of carbon nanotube fibers, J. Mater. Chem. 7 (15) (2019) 8790-8797.

[27] J. Foroughi, G.M. Spinks, G.G. Wallace, J. Oh, M.E. Kozlov, S. Fang, T. Mirfakhrai, J.D.W. Madden, M.K. Shin, S.J. Kim, R.H. Baughman, Torsional carbon nanotube Artificial muscles, Science 334 (6055) (2011) 494.

[28] K. Chen, W. Gao, S. Emaminejad, D. Kiriya, H. Ota, H.Y.Y. Nyein, K. Takei, A. Javey, Printed carbon nanotube electronics and sensor systems, Adv. Mater. 28 (22) (2016) 4397-4414.

[29] Applications of the Vantablack coating rangehttps://www.surreynanosystems. com/vantablack

[30] V. Jourdain, C. Bichara, Current understanding of the growth of carbon nanotubes in catalytic chemical vapour deposition, Carbon 58 (2013) 2-39.

[31] K.A. Shah, B.A. Tali, Synthesis of carbon nanotubes by catalytic chemical vapour deposition: a review on carbon sources, catalysts and substrates, Mater. Sci. Semicond. Process. 41 (2016) 67-82.

[32] E.C. Neyts, PECVD growth of carbon nanotubes: from experiment to simulation, J. Vac. Sci. Technol. B 30 (3) (2012) 030803

[33] M. Kumar, Y. Ando, Chemical vapor deposition of carbon nanotubes: a review on growth mechanism and mass production, J. Nanosci. Nanotechnol. 10 (6) (2010) 3739-3758.

[34] J. Robertson, G. Zhong, S. Hofmann, B.C. Bayer, C.S. Esconjauregui, H. Telg, C. Thomsen, Use of carbon nanotubes for VLSI interconnects, Diam. Relat. Mater. 18 (5-8) (2009) 957-962.

[35] J. Robertson, G. Zhong, H. Telg, C. Thomsen, J.M. Warner, G.A.D. Briggs, U. Detlaff, S. Roth, J. Dijon, Carbon nanotubes for interconnects in VLSI integrated circuits, Phys. Status Solidi B- Basic Solid State Phys. 245 (10) (2008) 2303-2307.

[36] J. Robertson, G. Zhong, C.S. Esconjauregui, B.C. Bayer, C. Zhang, M. Fouquet, S. Hofmann, Applications of carbon nanotubes grown by chemical vapor deposition, Jpn. J. Appl. Phys. 51 (1) (2012) 01AH01.

[37] Y. Awano, Carbon nanotube technologies for LSI via interconnects, IEICE Trans. Electron. E89C (11) (2006) 1499-1503.

[38] Y. Ando, Carbon nanotube: the inside story, J. Nanosci. Nanotechnol. 10 (6) (2010) 3726-3738

[39] Y. Ando, X. Zhao, T. Sugai, M. Kumar, Growing carbon nanotubes, Mater. Today 7 (10) (2004) 22-29.

[40] T.W. Ebbesen, P.M. Ajayan, Large-scale synthesis of carbon nanotubes, Nature (1992) 220-222.

[41] T. Guo, P. Nikolaev, A. Thess, D.T. Colbert, R.E. Smalley, Catalytic growth of single-walled manotubes by laser vaporization, Chem. Phys. Lett. 243 (1) (1995) 49-54.

[42] C.-M. Seah, S.-P. Chai, A.R. Mohamed, Synthesis of aligned carbon nanotubes, Carbon 49 (14) (2011) 4613-4635.

[43] S. Iijima, Helical microtubules of graphitic carbon, Nature 354 (6348) (1991) $56-58$.

[44] D.S. Bethune, C.H. Kiang, M.S. de Vries, G. Gorman, R. Savoy, J. Vazquez, R. Beyers, Cobalt-catalysed growth of carbon nanotubes with single-atomic-layer walls, Nature 363 (6430) (1993) 605-607.

[45] M. Endo, K. Takeuchi, S. Igarashi, K. Kobori, M. Shiraishi, H.W. Kroto, The production and structure of pyrolytic carbon nanotubes (pents), J. Phys. Chem. Solids 54 (12) (1993) 1841-1848.

[46] H. Hiura, T.W. Ebbesen, K. Tanigaki, H. Takahashi, Raman studies of carbon nanotubes, Chem. Phys. Lett. 202 (6) (1993) 509-512.

[47] L.A. Chernozatonskii, Z.J. Kosakovskaja, A.N. Kiselev, N.A. Kiselev, Carbon films of oriented multilayered nanotubes deposited on $\mathrm{KBr}$ and glass by electron beam evaporation, Chem. Phys. Lett. 228 (1) (1994) 94-99.

[48] M.J. Bronikowski, P.A. Willis, D.T. Colbert, K.A. Smith, R.E. Smalley, Gas-phase production of carbon single-walled nanotubes from carbon monoxide via the HiPco process: a parametric study, J. Vac. Sci. Technol. A 19 (4) (2001) 1800-1805.

[49] P.G. Collins, M.S. Arnold, P. Avouris, Engineering carbon nanotubes and nanotube circuits using electrical breakdown, Science 292 (5517) (2001) 706.

[50] B.O. Boskovic, V. Stolojan, R.U.A. Khan, S. Haq, S.R.P. Silva, Large-area synthesis of carbon nanofibres at room temperature, Nat. Mater. 1 (3) (2002) 165-168.

[51] K. Hata, D.N. Futaba, K. Mizuno, T. Namai, M. Yumura, S. Iijima, Water-assisted highly efficient synthesis of impurity-free single-waited carbon nanotubes, Science 306 (5700) (2004) 1362-1364.

[52] M. Zhang, S. Fang, A.A. Zakhidov, S.B. Lee, A.E. Aliev, C.D. Williams, K.R. Atkinson, R.H. Baughman, Strong, transparent, multifunctional, carbon nan otube sheets, Science 309 (5738) (2005) 1215

[53] G.Y. Chen, V. Stolojan, S.R.P. Silva, Top-down heating for low substrate temperature synthesis of carbon nanotubes, J. Nanosci. Nanotechnol. 10 (6) (2010) 3952-3958.

[54] R. Zhang, Y. Zhang, Q. Zhang, H. Xie, W. Qian, F. Wei, Growth of half-meter long carbon nanotubes based on schulz-flory distribution, ACS Nano 7 (7) (2013) 6156-6161.

[55] M.R. Arcila-Velez, J. Zhu, A. Childress, M. Karakaya, R. Podila, A.M. Rao, M.E. Roberts, Roll-to-roll synthesis of vertically aligned carbon nanotube electrodes for electrical double layer capacitors, Nano Energy 8 (2014) 9-16. 
[56] M. Ahmad, J.V. Anguita, C. Ducati, J.D. Carey, S.R.P. Silva, Protected catalyst growth of graphene and carbon nanotubes, Carbon 149 (2019) 71-85.

[57] Y.Y. Tan, K. Jayawardena, A. Adikaari, L.W. Tan, J.V. Anguita, S.J. Henley, V. Stolojan, J.D. Carey, S.R.P. Silva, Photo-thermal chemical vapor deposition growth of graphene, Carbon 50 (2) (2012) 668-673.

[58] G.Y. Chen, B. Jensen, V. Stolojan, S.R.P. Silva, Growth of carbon nanotubes at temperatures compatible with integrated circuit technologies, Carbon 49 (1) (2011) 280-285.

[59] N.G. Shang, Y.Y. Tan, V. Stolojan, P. Papakonstantinou, S.R.P. Silva, High-rate low-temperature growth of vertically aligned carbon nanotubes, Nanotechnology 21 (50) (2010) 6.

[60] M. Ahmad, J.V. Anguita, V. Stolojan, J.D. Carey, S.R.P. Silva, Efficient coupling of optical energy for rapid catalyzed nanomaterial growth: high-quality carbon nanotube synthesis at low substrate temperatures, ACS Appl. Mater. Interfaces 5 (9) (2013) 3861-3866.

[61] J.V. Anguita, D.C. Cox, M. Ahmad, Y.Y. Tan, J. Allam, S.R.P. Silva, Highly transmissive carbon nanotube forests grown at low substrate temperature, Adv. Funct. Mater. 23 (44) (2013) 5502-5509.

[62] M. Su, B. Zheng, J. Liu, A scalable CVD method for the synthesis of single-walled carbon nanotubes with high catalyst productivity, Chem. Phys. Lett. 322 (5) (2000) 321-326.

[63] R. Andrews, D. Jacques, A.M. Rao, F. Derbyshire, D. Qian, X. Fan, E.C. Dickey, J. Chen, Continuous production of aligned carbon nanotubes: a step closer to commercial realization, Chem. Phys. Lett. 303 (5) (1999) 467-474.

[64] C. Castro, M. Pinault, S. Coste-Leconte, D. Porterat, N. Bendiab, C. Reynaud, M. Mayne-L'Hermite, Dynamics of catalyst particle formation and multi-walled carbon nanotube growth in aerosol-assisted catalytic chemical vapor deposition, Carbon 48 (13) (2010) 3807-3816.

[65] S.S. Meysami, A.A. Koós, F. Dillon, M. Dutta, N. Grobert, Aerosol-assisted chemical vapour deposition synthesis of multi-wall carbon nanotubes: III. Towards upscaling, Carbon 88 (2015) 148-156.

[66] R. Alexandrescu, A. Crunteanu, R.E. Morjan, I. Morjan, F. Rohmund, L.K.L. Falk, G. Ledoux, F. Huisken, Synthesis of carbon nanotubes by $\mathrm{CO}_{2}$-laser-assisted chemical vapour deposition, Infrared Phys. Technol. 44 (1) (2003) 43-50.

[67] S. Maruyama, Y. Miyauchi, Y. Murakami, S. Chiashi, Optical characterization of single-walled carbon nanotubes synthesized by catalytic decomposition of alcohol, New J. Phys. 5 (2003) 12.

[68] J.-P. Tessonnier, D.S. Su, Recent progress on the growth mechanism of carbon nanotubes: a review, Chemsuschem 4 (7) (2011) 824-847.

[69] H.M. Cheng, F. Li, G. Su, H.Y. Pan, L.L. He, X. Sun, M.S. Dresselhaus, Large-scale and low-cost synthesis of single-walled carbon nanotubes by the catalytic pyrolysis of hydrocarbons, Appl. Phys. Lett. 72 (25) (1998) 3282-3284.

[70] B. Yu, C. Liu, P.-X. Hou, Y. Tian, S. Li, B. Liu, F. Li, E.I. Kauppinen, H.-M. Cheng, Bulk synthesis of large diameter semiconducting single-walled carbon nanotubes by oxygen-assisted floating catalyst chemical vapor deposition, J. Am. Chem. Soc. 133 (14) (2011) 5232-5235

[71] T. Kinoshita, M. Karita, T. Nakano, Y. Inoue, Two step floating catalyst chemical vapor deposition including in situ fabrication of catalyst nanoparticles and carbon nanotube forest growth with low impurity level, Carbon 144 (2019) 152-160.

[72] Z.F. Ren, Z.P. Huang, D.Z. Wang, J.G. Wen, J.W. Xu, J.H. Wang, L.E. Calvet, J. Chen, J.F. Klemic, M.A. Reed, Growth of a single freestanding multiwall carbon nanotube on each nanonickel dot, Appl. Phys. Lett. 75 (8) (1999) 1086-1088.

[73] Z.F. Ren, Z.P. Huang, J.W. Xu, J.H. Wang, P. Bush, M.P. Siegal, P.N. Provencio, Synthesis of large arrays of well-aligned carbon nanotubes on glass, Science 282 (5391) (1998) 1105-1107.

[74] M. Yudasaka, R. Kikuchi, T. Matsui, Y. Ohki, S. Yoshimura, E. Ota, Specific conditions for Ni catalyzed carbon nanotube growth by chemical-vapor-deposition, Appl. Phys. Lett. 67 (17) (1995) 2477-2479.

[75] M. Yudasaka, R. Kikuchi, Y. Ohki, E. Ota, S. Yoshimura, Behavior of Ni in carbon nanotube nucleation, Appl. Phys. Lett. 70 (14) (1997) 1817-1818.

[76] M. Chhowalla, K.B.K. Teo, C. Ducati, N.L. Rupesinghe, G.A.J. Amaratunga, A.C Ferrari, D. Roy, J. Robertson, W.I. Milne, Growth process conditions of vertically aligned carbon nanotubes using plasma enhanced chemical vapor deposition, J. Appl. Phys. 90 (10) (2001) 5308-5317.

[77] J.S. Chen, V. Stolojan, S.R.P. Silva, Towards type-selective carbon nanotube growth at low substrate temperature via photo-thermal chemical vapour deposition, Carbon 84 (2015) 409-418.

[78] K.E. Kim, K.J. Kim, W.S. Jung, S.Y. Bae, J. Park, J. Choi, J. Choo, Investigation on the temperature-dependent growth rate of carbon nanotubes using chemical vapor deposition of ferrocene and acetylene, Chem. Phys. Lett. 401 (4-6) (2005) 459-464.

[79] M. Ahmad, J.V. Anguita, V. Stolojan, T. Corless, J.-S. Chen, J.D. Carey, S.R.P. Silva, High quality carbon nanotubes on conductive substrates grown at low temperatures, Adv. Funct. Mater. 25 (28) (2015) 4419-4429.

[80] A.V. Melechko, V.I. Merkulov, T.E. McKnight, M.A. Guillorn, K.L. Klein, D.H. Lowndes, M.L. Simpson, Vertically aligned carbon nanofibers and related structures: controlled synthesis and directed assembly, J. Appl. Phys. 97 (4) (2005) 39.

[81] V. Stolojan, Y. Tison, G.Y. Chen, R. Silva, Controlled growth-reversal of catalytic carbon nanotubes under electron-beam irradiation, Nano Lett. 6 (9) (2006) 1837-1841

[82] S. Maruyama, R. Kojima, Y. Miyauchi, S. Chiashi, M. Kohno, Low-temperature synthesis of high-purity single-walled carbon nanotubes from alcohol, Chem. Phys. Lett. 360 (3-4) (2002) 229-234.

[83] R. Sen, A. Govindaraj, C.N.R. Rao, Carbon nanotubes by the metallocene route, Chem. Phys. Lett. 267 (3-4) (1997) 276-280.
[84] M. Kumar, Y. Ando, A simple method of producing aligned carbon nanotubes from an unconventional precursor - Camphor, Chem. Phys. Lett. 374 (5-6) (2003) 521-526.

[85] Q.W. Li, H. Yan, J. Zhang, Z.F. Liu, Effect of hydrocarbons precursors on the formation of carbon nanotubes in chemical vapor deposition, Carbon 42 (4) (2004) 829-835.

[86] Q. Li, X. Zhang, R.F. DePaula, L. Zheng, Y. Zhao, L. Stan, T.G. Holesinger, P.N. Arendt, D.E. Peterson, Y.T. Zhu, Sustained growth of ultralong carbon nanotube arrays for fiber spinning, Adv. Mater. 18 (23) (2006) 3160-3163.

[87] A.M. Cassell, J.A. Raymakers, J. Kong, H.J. Dai, Large scale CVD synthesis of single-walled carbon nanotubes, J. Phys. Chem. B 103 (31) (1999) 6484-6492

[88] H.J. Dai, J. Kong, C.W. Zhou, N. Franklin, T. Tombler, A. Cassell, S.S. Fan, M. Chapline, Controlled chemical routes to nanotube architectures, physics, and devices, J. Phys. Chem. B 103 (51) (1999) 11246-11255.

[89] J. Kong, A.M. Cassell, H.J. Dai, Chemical vapor deposition of methane for single-walled carbon nanotubes, Chem. Phys. Lett. 292 (4-6) (1998) 567-574.

[90] J. Kong, H.T. Soh, A.M. Cassell, C.F. Quate, H.J. Dai, Synthesis of individua single-walled carbon nanotubes on patterned silicon wafers, Nature 395 (6705) (1998) 878-881.

[91] D. Yuan, L. Ding, H. Chu, Y. Feng, T.P. McNicholas, J. Liu, Horizontally aligned single-walled carbon nanotube on quartz from a large variety of metal catalysts, Nano Lett. 8 (8) (2008) 2576-2579.

[92] R. Seidel, G.S. Duesberg, E. Unger, A.P. Graham, M. Liebau, F. Kreupl, Chemical vapor deposition growth of single-walled carbon nanotubes at 600 degrees $\mathrm{C}$ and a simple growth model, J. Phys. Chem. B 108 (6) (2004) 1888-1893.

[93] E.R. Meshot, D.L. Plata, S. Tawfick, Y. Zhang, E.A. Verploegen, A.J. Hart, Engineering vertically aligned carbon nanotube growth by decoupled thermal treatment of precursor and catalyst, ACS Nano 3 (9) (2009) 2477-2486.

[94] K.Y. Lee, S.I. Honda, M. Katayama, T. Miyake, K. Himuro, K. Oura, J.G. Lee, H. Mori, T. Hirao, Vertically aligned growth of carbon nanotubes with long length and high density, J. Vac. Sci. Technol. B 23 (4) (2005) 1450-1453.

[95] J.D. Carey, L.L. Ong, S.R.P. Silva, Formation of low-temperature self-organized nanoscale nickel metal islands, Nanotechnology 14 (11) (2003) 1223-1227.

[96] G.D. Nessim, A.J. Hart, J.S. Kim, D. Acquaviva, J. Oh, C.D. Morgan, M. Seita, J.S. Leib, C.V. Thompson, Tuning of vertically-aligned carbon nanotube diameter and areal density through catalyst pre-treatment, Nano Lett. 8 (11) (2008) 3587-3593.

[97] H. Ago, K. Nakamura, N. Uehara, M. Tsuji, Roles of metal-support interaction in growth of single- and double-walled carbon nanotubes studied with diameter-controlled iron particles supported on MgO, J. Phys. Chem. B 108 (49) (2004) 18908-18915.

[98] Y.J. Jung, B.Q. Wei, R. Vajtai, P.M. Ajayan, Mechanism of selective growth of carbon nanotubes on $\mathrm{SiO}_{2} / \mathrm{Si}$ patterns, Nano Lett. 3 (4) (2003) 561-564.

[99] S. Esconjauregui, M. Fouquet, B.C. Bayer, C. Ducati, R. Smajda, S. Hofmann, J. Robertson, Growth of ultrahigh density vertically aligned carbon nanotube forests for interconnects, ACS Nano 4 (12) (2010) 7431-7436.

[100] D. Yokoyama, T. Iwasaki, T. Yoshida, H. Kawarada, S. Sato, T. Hyakushima, M. Nihei, Y. Awano, Low temperature grown carbon nanotube interconnects using inner shells by chemical mechanical polishing, Appl. Phys. Lett. 91 (26) (2007) 263101.

[101] F. Kreupl, A.P. Graham, G.S. Duesberg, W. Steinhogl, M. Liebau, E. Unger, W. Honlein, Carbon nanotubes in interconnect applications, Microelectron. Eng. 64 (1-4) (2002) 399-408.

[102] H. Okuno, A. Fournier, E. Quesnel, V. Muffato, H. Le Poche, M. Fayolle, J. Dijon, CNT integration on different materials suitable for VLSI interconnects, Compt. Rendus Phys. 11(5-6) 381-388.

[103] M.H. van der Veen, B. Vereecke, C. Huyghebaert, D.J. Cott, M. Sugiura, Y. Kashiwagi, L. Teugels, R. Caluwaerts, N. Chiodarelli, P.M. Vereecken, G.P. Beyer, M.M. Heyns, S. De Gendt, Z. Tokei, Electrical characterization of CNT contacts with Cu Damascene top contact, Microelectron. Eng. 106 (2013) 106-111.

[104] J. Li, Q. Ye, A. Cassell, H.T. Ng, R. Stevens, J. Han, M. Meyyappan, Bottom-up approach for carbon nanotube interconnects, Appl. Phys. Lett. 82 (15) (2003) 2491-2493.

[105] A. Reina, M. Hofmann, D. Zhu, J. Kong, Growth mechanism of long and horizontally aligned carbon nanotubes by chemical vapor deposition, J. Phys. Chem. C 111 (20) (2007) 7292-7297.

[106] Y. Chai, Z. Xiao, P.C.H. Chan, Horizontally aligned carbon nanotube bundles for interconnect application: diameter-dependent contact resistance and mean free path, Nanotechnology 21 (23) (2010).

[107] A. Cao, R. Baskaran, M.J. Frederick, K. Turner, P.M. Ajayan, G. Ramanath, Direction-selective and length-tunable in-plane growth of carbon nanotubes, Adv. Mater. 15 (13) (2003) 1105-1109.

[108] H. Butt, T. Butler, Y. Montelongo, R. Rajesekharan, T.D. Wilkinson, G.A.J. Amaratunga, Continuous diffraction patterns from circular arrays of carbon nanotubes, Appl. Phys. Lett. 101 (25) (2012) 251102.

[109] G. Chen, B. Dodson, D.M. Hedges, S.C. Steffensen, J.N. Harb, C. Puleo, C. Galligan, J. Ashe, R.R. Vanfleet, R.C. Davis, Fabrication of high aspect ratio millimeter-tall free-standing carbon nanotube-based microelectrode arrays, ACS Biomater. Sci. Eng. 4 (5) (2018) 1900-1907.

[110] J. Clark, Y. Chen, S.R.P. Silva, Low impedance functionalised carbon nanotube electrode arrays for electrochemical detection, Electroanalysis 28 (1) (2016) $58-62$.

[111] J. Clark, J.V. Anguita, Y. Chen, S.R.P. Silva, Optical nanostructures in 2D for wide-diameter and broadband beam collimation, Sci. Rep. 6 (2016) 10.

[112] C.E. Giusca, Y. Tison, V. Stolojan, E. Borowiak-Palen, S.R.P. Silva, Inner-tube chirality determination for double-walled carbon nanotubes by scanning tunneling microscopy, Nano Lett. 7 (5) (2007) 1232-1239. 
[113] E. Mora, J.M. Pigos, F. Ding, B.I. Yakobson, A.R. Harutyunyan, Low-temperature single-wall carbon nanotubes synthesis: feedstock decomposition limited growth, J. Am. Chem. Soc. 130 (36) (2008) 11840-11841.

[114] G.D. Nessim, M. Seita, K.P. O'Brien, A.J. Hart, R.K. Bonaparte, R.R. Mitchell, C.V. Thompson, Low temperature synthesis of vertically aligned carbon nanotubes with electrical contact to metallic substrates enabled by thermal decomposition of the carbon feedstock, Nano Lett. 9 (10) (2009) 3398-3405.

[115] C. Bower, W. Zhu, S.H. Jin, O. Zhou, Plasma-induced alignment of carbon nanotubes, Appl. Phys. Lett. 77 (6) (2000) 830-832.

[116] V.I. Merkulov, D.H. Lowndes, Y.Y. Wei, G. Eres, E. Voelkl, Patterned growth of individual and multiple vertically aligned carbon nanofibers, Appl. Phys. Lett. 76 (24) (2000) 3555-3557.

[117] K.B.K. Teo, M. Chhowalla, G.A.J. Amaratunga, W.I. Milne, D.G. Hasko, G. Pirio, P. Legagneux, F. Wyczisk, D. Pribat, Uniform patterned growth of carbon nanotubes without surface carbon, Appl. Phys. Lett. 79 (10) (2001) 1534-1536.

[118] N. Halonen, A. Sápi, L. Nagy, R. Puskás, A.-R. Leino, J. Mäklin, J. Kukkola, G. Tóth, M.-C. Wu, H.-C. Liao, W.-F. Su, A. Shchukarev, J.-P. Mikkola, Á. Kukovecz, Z. Kónya, K. Kordás, Low-temperature growth of multi-walled carbon nanotubes by thermal CVD, Phys. Status Solidi 248 (11) (2011) 2500-2503.

[119] R. Cartwright, S. Esconjauregui, D. Hardeman, S. Bhardwaj, R. Weatherup, Y. Guo, L. D’Arsié, B. Bayer, P. Kidambi, S. Hofmann, E. Wright, J. Clarke, D. Oakes, C. Cepek, J. Robertson, Low temperature growth of carbon nanotubes on tetrahedral amorphous carbon using $\mathrm{Fe}-\mathrm{Cu}$ catalyst, Carbon 81 (2015) 639-649.

[120] A. Magrez, J.W. Seo, R. Smajda, B. Korbely, J.C. Andresen, M. Mionić, S. Casimirius, L. Forró, Low-temperature, highly efficient growth of carbon nanotubes on functional materials by an oxidative dehydrogenation reaction, ACS Nano 4 (7) (2010) 3702-3708.

[121] R. Li, E.F. Antunes, E. Kalfon-Cohen, A. Kudo, L. Acauan, W.-C.D. Yang, C. Wang, K. Cui, A.H. Liotta, A.G. Rajan, J. Gardener, D.C. Bell, M.S. Strano, J.A. Liddle, R. Sharma, B.L. Wardle, Low-temperature growth of carbon nanotubes catalyzed by sodium-based ingredients, Angew. Chem. Int. Ed. 58 (27) (2019) 9204-9209.

[122] Y.-M. Liu, Y. Sung, T.-T. Chen, H.-T. Wang, M.-D. Ger, Low temperature growth of carbon nanotubes by thermal chemical vapor deposition using non-isothermal deposited Ni-P-Pd as co-catalyst, Mater. Chem. Phys. 106 (2) (2007) 399-405.

[123] Y. Sung, M.D. Ger, Y.H. Chou, Novel route to deposit metallic dot array or thin film on the conducting and insulating substrates, J. Mater. Sci. Lett. 22 (21) (2003) 1515-1518.

[124] T.-T. Chen, Y.-M. Liu, Y. Sung, H.-T. Wang, M.-D. Ger, Experimental investigation on carbon nanotube grown by thermal chemical vapor deposition using non-isothermal deposited catalysts, Mater. Chem. Phys. 97 (2) (2006) 511-516.

[125] T.-Y. Tsai, N.-H. Tai, K.C. Chen, S.H. Lee, L.H. Chan, Y.Y. Chang, Growth of vertically aligned carbon nanotubes on glass substrate at $450{ }^{\circ} \mathrm{C}$ through the thermal chemical vapor deposition method, Diam. Relat. Mater. 18 (2) (2009) 307-311.

[126] T. Goichi, P. Lujun, A. Seiji, N. Yoshikazu, Vertically aligned carbon nanotubes grown at low temperatures for use in displays, Jpn. J. Appl. Phys. 44 (7S) (2005) 5642

[127] H. Sugime, S. Esconjauregui, J. Yang, L. D'Arsie, R.A. Oliver, S. Bhardwaj, C. Cepek, J. Robertson, Low temperature growth of ultra-high mass density carbon nanotube forests on conductive supports, Appl. Phys. Lett. 103 (7) (2013).

[128] H. Sugime, S. Esconjauregui, L. D’Arsié, J. Yang, A.W. Robertson, R.A. Oliver, S. Bhardwaj, C. Cepek, J. Robertson, Low-temperature growth of carbon nanotube forests consisting of tubes with narrow inner spacing using $\mathrm{Co} / \mathrm{Al} / \mathrm{Mo}$ catalyst on conductive supports, ACS Appl. Mater. Interfaces 7 (30) (2015) 16819-16827.

[129] H. Sugime, S. Esconjauregui, J. Yang, L. D’Arsié, R.A. Oliver, S. Bhardwaj, C. Cepek, J. Robertson, Low temperature growth of ultra-high mass density carbon nanotube forests on conductive supports, Appl. Phys. Lett. 103 (7) (2013) 073116.

[130] N. Na, D.Y. Kim, Y.-G. So, Y. Ikuhara, S. Noda, Simple and engineered process yielding carbon nanotube arrays with $1.2 \times 1013 \mathrm{~cm}-2$ wall density on conductive underlayer at $400^{\circ} \mathrm{C}$, Carbon 81 (2015) 773-781.

[131] H. Almkhelfe, J. Carpena-Núñez, T.C. Back, P.B. Amama, Gaseous product mixture from Fischer-Tropsch synthesis as an efficient carbon feedstock for low temperature CVD growth of carbon nanotube carpets, Nanoscale 8 (27) (2016) 13476-13487.

[132] S. Vollebregt, R. Ishihara, J. Cingel, K. Beenakker, Low-temperature bottom-up integration of carbon nanotubes for vertical interconnects in monolithic 3D integrated circuits, 2011 IEEE International 3D Systems Integration Conference (3DIC), 2011, IEEE International, 2012, pp. 1-4.

[133] S. Vollebregt, F.D. Tichelaar, H. Schellevis, C.I.M. Beenakker, R. Ishihara, Carbon nanotube vertical interconnects fabricated at temperatures as low as $350^{\circ} \mathrm{C}$ Carbon 71 (2014) 249-256.

[134] T.-K. Chuang, K.S. Anuratha, J.-Y. Lin, K.-C. Huang, C.-H. Su, C.-K. Hsieh, Low temperature growth of carbon nanotubes using chemical bath deposited $\mathrm{Ni}(\mathrm{OH}) 2$ - an efficient Pt-free counter electrodes for dye-sensitized solar cells, Surf. Coat. Technol. 344 (2018) 534-540.

[135] X. Jin, J. Lim, Y. Ha, N.H. Kwon, H. Shin, I.Y. Kim, N.-S. Lee, M.H. Kim, H. Kim, S.-J. Hwang, A critical role of catalyst morphology in low-temperature synthesis of carbon nanotube-transition metal oxide nanocomposite, Nanoscale 9 (34) (2017) 12416-12424

[136] J. Zhang, A. Tahmasebi, J.E. Omoriyekomwan, J. Yu, Production of carbon nan otubes on bio-char at low temperature via microwave-assisted CVD using $\mathrm{Ni}$ catalyst, Diam. Relat. Mater. 91 (2019) 98-106.

[137] M. Nihei, A. Kawabata, D. Kondo, M. Horibe, S. Sato, Y. Awano, Electrical prop erties of carbon nanotube bundles for future via interconnects, Jpn.
J. Appl. Phys. Part 1-Regul. Papers Short Notes Rev. Papers 44 (4A) (2005) 1626-1628.

[138] Y. Awano, S. Sato, D. Kondo, M. Ohfuti, A. Kawabata, M. Nihei, N. Yokoyama, Carbon nanotube via interconnect technologies: size-classified catalyst nanoparticles and low-resistance ohmic contact formation, Phys. Status Solidi A- Appl. Mater. Sci. 203 (14) (2006) 3611-3616.

[139] Y. Daisuke, I. Takayuki, I. Kentaro, S. Shintaro, H. Takashi, N. Mizuhisa, A. Yuji, K. Hiroshi, Electrical properties of carbon nanotubes grown at a low temperature for use as interconnects, Jpn. J. Appl. Phys. 47 (4R) (2008) 1985.

[140] K. Masayuki, S. Naoshi, Y. Yuichi, S. Mariko, S. Shintaro, N. Mizuhisa, S. Tadashi, A. Yuji, Low-temperature growth of multiwalled carbon nanotubes by surface-wave plasma-enhanced chemical vapor deposition using catalyst nanoparticles, Jpn. J. Appl. Phys. 48 (9R) (2009) 090205.

[141] Y. Yamazaki, N. Sakuma, M. Katagiri, M. Suzuki, T. Sakai, S. Sato, M. Nihei, Y. Awano, High-quality carbon nanotube growth at low temperature by pulse-excited remote plasma chemical vapor deposition, APEX 1 (3) (2008).

[142] S. Sato, A. Kawabata, T. Nozue, D. Kondo, T. Murakami, T. Hyakushima, M. Nihei, Y. Awano, Fabrication of carbon nanotube via interconnects at low temperature and their robustness over a high-density current, Sens. Mater. 21 (7) (2009) 373-383.

[143] M. Katagiri, N. Sakuma, M. Suzuki, T. Sakai, S. Sato, T. Hyakushima, M. Nihei, Y. Awano, Carbon nanotube vias fabricated by remote plasma-enhanced chemical vapor deposition, Jpn. J. Appl. Phys. 47 (4) (2008) 2024-2027.

[144] S. Sato, M. Nihei, A. Mimura, A. Kawabata, D. Kondo, H. Shioya, W. Taisuke, M. Mishima, M. Ohfuti, Y. Awano, Novel approach to fabricating carbon nanotube via interconnects using size-controlled catalyst nanoparticles, Proceedings of the IEEE 2006 International Interconnect Technology Conference, Ieee, Electron Devices Soc \& Reliability Group, New York, 2006, pp. 230-232.

[145] Y. Yamazaki, M. Katagiri, N. Sakuma, M. Suzuki, S. Sato, M. Nihei, M. Wada, N. Matsunaga, T. Sakai, Y. Awano, Synthesis of a closely packed carbon nanotube forest by a multi-step growth method using plasma-based chemical vapor deposition, APEX 3 (5) (2010).

[146] S. Li, Y. Liu, S. Zhou, C. Zhou, M. Chan, Contact resistance reduction of carbon nanotube via through $\mathrm{O} 2$ plasma post-synthesis treatment, J. Mater. Chem. C 6 (18) (2018) 5039-5045.

[147] S. Hofmann, C. Ducati, J. Robertson, B. Kleinsorge, Low-temperature growth of carbon nanotubes by plasma-enhanced chemical vapor deposition, Appl. Phys. Lett. 83 (1) (2003) 135-137.

[148] S. Li, C. Zhou, S. Raju, M. Chan, Catalyst design for high-density and low-temperature CNT synthesis on conductive Ti silicide substrate, Diam. Relat. Mater. 75 (2017) 39-43.

[149] N. Chiodarelli, S. Masahito, Y. Kashiwagi, Y. Li, K. Arstila, O. Richard, D.J. Cott, M. Heyns, S. De Gendt, G. Groeseneken, P.M. Vereecken, Measuring the electrical resistivity and contact resistance of vertical carbon nanotube bundles for application as interconnects, Nanotechnology 22 (8) (2011).

[150] N. Chiodarelli, Y. Li, D.J. Cott, S. Mertens, N. Peys, M. Heyns, S. De Gendt, G. Groeseneken, P.M. Vereecken, Integration and electrical characterization of carbon nanotube via interconnects, Microelectron. Eng. 88 (5) (2011) 837-843.

[151] N. Chiodarelli, M.H. Veen, B. Vereecke, D.J. Cott, G. Groeseneken, P.M. Vereecken, C. Huyghebaert, Z. Tokeï, Carbon nanotube interconnects: electrical characterization of $150 \mathrm{~nm}$ CNT contacts with Cu damascene top contact, 2011 IEEE International Interconnect Technology Conference, 2011, pp. 1-3.

[152] J. Vanpaemel, M. Sugiura, Y. Barbarin, S. De Gendt, Z. Tökei, P.M. Vereecken, M.H. van der Veen, Growth and integration challenges for carbon nanotube in terconnects, Microelectron. Eng. 120 (2014) 188-193.

[153] M. Baro, D. Gogoi, A.R. Pal, N.C. Adhikary, H. Bailung, J. Chutia, Pulsed PECVD for low-temperature growth of vertically aligned carbon nanotubes, Chem. Vap. Depos. 20 (4-5-6) (2014) 161-169.

[154] M. Chen, C.-M. Chen, C.-F. Chen, Preparation of high yield multi-walled carbon nanotubes by microwave plasma chemical vapor deposition at low temperature, J. Mater. Sci. 37 (17) (2002) 3561-3567.

[155] A. Roy, D. Das, Low temperature growth of carbon nanotubes with aligned multiwalls by microwave plasma-CVD, AIP Conf. Proc. 1832 (1) (2017) 080028.

[156] A. Roy, D. Das, Low temperature growth of carbon nanotubes by microwave plasma stimulated by $\mathrm{CO} 2$ as weak oxidant and guided by shadow masking, Diam. Relat. Mater. 88 (2018) 204-214.

[157] Y. Xiao, Z. Ahmed, Z. Ma, C. Zhou, L. Zhang, M. Chan, Low temperature synthesis of high-density carbon nanotubes on insulating substrate, Nanomaterials 9 (3) (2019).

[158] X. Ji, W. Zhang, X. Li, H. Yu, H. Dong, A novel hybrid method combining ASP with PECVD for in-situ low temperature synthesis of vertically aligned carbon nanotube films, Diam. Relat. Mater. 77 (2017) 16-24.

[159] K. Mugadza, V.O. Nyamori, G.T. Mola, R.H. Simoyi, P.G. Ndungu, Low temper ature synthesis of multiwalled carbon nanotubes and incorporation into an organic solar cell, J. Exp. Nanosci. 12 (1) (2017) 363-383.

[160] E. Raymundo-Piñero, P. Azaïs, T. Cacciaguerra, D. Cazorla-Amorós, A. Linares-Solano, F. Béguin, $\mathrm{KOH}$ and $\mathrm{NaOH}$ activation mechanisms of multiwalled carbon nanotubes with different structural organisation, Carbon 43 (4) (2005) 786-795

[161] B. Adeniran, R. Mokaya, Low temperature synthesized carbon nanotube superstructures with superior $\mathrm{CO} 2$ and hydrogen storage capacity, J. Mater. Chem. 3 (9) (2015) 5148-5161.

[162] M. Ahmad, Carbon Nanotube Based Integrated Circuit Interconnects, Advanced Technology Institute, Faculty of Engineering and Physical Sciences, University of Surrey, 2013, p. 199.

[163] M.S. Shamsudin, N.A. Asli, S. Abdullah, S.Y.S. Yahya, M. Rusop, Effect of synthesis temperature on the growth iron-filled carbon nanotubes as evidenced by structural, micro-Raman, and thermogravimetric analyses, Adv. Condens. Matter Phys. (2012) (Article ID 420619). 
[164] Y.T. Lee, J. Park, Y.S. Choi, H. Ryu, H.J. Lee, Temperature-dependent growth of vertically aligned carbon nanotubes in the range 800-1100 degrees C, J. Phys. Chem. B 106 (31) (2002) 7614-7618.

[165] J. Ziebro, I. Lukasiewicz, E. Borowiak-Palen, B. Michalkiewicz, Low temperature growth of carbon nanotubes from methane catalytic decomposition over nickel supported on a zeolite, Nanotechnology 21 (14) (2010).

[166] L. Qu, F. Du, L. Dai, Preferential syntheses of semiconducting vertically aligned single-walled carbon nanotubes for direct use in FETs, Nano Lett. 8 (9) (2008) 2682-2687.

[167] E.J. Bae, Y.-S. Min, D. Kang, J.-H. Ko, W. Park, Low-temperature growth of single-walled carbon nanotubes by plasma enhanced chemical vapor deposition, Chem. Mater. 17 (20) (2005) 5141-5145.

[168] M. Cantoro, S. Hofmann, S. Pisana, V. Scardaci, A. Parvez, C. Ducati, A.C. Ferrari, A.M. Blackburn, K.-Y. Wang, J. Robertson, Catalytic chemical vapor deposition of single-wall carbon nanotubes at low temperatures, Nano Lett. 6 (6) (2006) 1107-1112.

[169] T. Maruyama, A. Kozawa, T. Saida, S. Naritsuka, S. Iijima, Low temperature growth of single-walled carbon nanotubes from Rh catalysts, Carbon 116 (2017) 128-132.

[170] T. Okada, T. Saida, S. Naritsuka, T. Maruyama, Low-temperature synthesis of single-walled carbon nanotubes with Co catalysts via alcohol catalytic chemica vapor deposition under high vacuum, Mater. Today Commun. 19 (2019) 51-55.

[171] S. Zhang, D. Lin, W. Liu, Y. Yu, J. Zhang, Growth of single-walled carbon nanotubes with different chirality on same solid cobalt catalysts at low temperature, Small 0 (0) (2019) 1903896.

[172] S. Zhang, L. Kang, X. Wang, L. Tong, L. Yang, Z. Wang, K. Qi, S. Deng, Q. Li, X. Bai, F. Ding, J. Zhang, Arrays of horizontal carbon nanotubes of controlled chirality grown using designed catalysts, Nature 543 (2017) 234.

[173] V. Jelicic, M. Magno, K. Chikkadi, C. Roman, C. Hierold, V. Bilas, L. Benini, Towards Internet of Things for event-driven low-power gas sensing using carbon nanotubes, 2015 6th International Workshop on Advances in Sensors and Interfaces, IWASI, 2015, pp. 271-276.

[174] Y.Q. Zhan, Y.F. Mei, L.R. Zheng, Materials capability and device performance in flexible electronics for the Internet of Things, J. Mater. Chem. C 2 (7) (2014) $1220-1232$.

[175] C.A. Hewitt, A.B. Kaiser, S. Roth, M. Craps, R. Czerw, D.L. Carroll, Multilayered carbon nanotube/polymer composite based thermoelectric fabrics, Nano Lett. 12 (3) (2012) 1307-1310.

[176] S. Ahmad, D. Copic, C. George, M. De Volder, Hierarchical assemblies of carbon nanotubes for ultraflexible Li-ion batteries, Adv. Mater. 28 (31) (2016) 6705-6710.

[177] J.G.D. Hester, M.M. Tentzeris, Y. Fang, UHF lumped element model of a fully-inkjet-printed single-wall-carbon-nanotube-based inter-digitated electrodes breath sensor, 2016 IEEE International Symposium on Antennas and Propagation, APSURSI, 2016, pp. 1959-1960.

[178] W.A. Gaviria Rojas, J.J. McMorrow, M.L. Geier, Q. Tang, C.H. Kim, T.J. Marks, M.C. Hersam, Solution-processed carbon nanotube true random number generator, Nano Lett. 17 (8) (2017) 4976-4981.

[179] G.D. Nessim, M. Seita, K.P. O’Brien, A.J. Hart, R.K. Bonaparte, R.R. Mitchell, C.V. Thompson, Low temperature synthesis of vertically aligned carbon nanotubes with electrical contact to metallic substrates enabled by thermal decom position of the carbon feedstock, Nano Lett. 9 (10) (2009) 3398-3405. 